\title{
Involving men in maternity care: South Africa
}

\author{
Busi Kunene \\ Mags Beksinska \\ Simphiwe Zondi \\ Nobuhle Mthembu \\ Saiqa Mullick \\ Population Council
}

See next page for additional authors

Follow this and additional works at: https://knowledgecommons.popcouncil.org/departments_sbsr-rh

Part of the Demography, Population, and Ecology Commons, International Public Health Commons, Maternal and Child Health Commons, Public Health Education and Promotion Commons, and the Women's Health Commons

How does access to this work benefit you? Let us know!

\section{Recommended Citation}

Kunene, Busi, Mags Beksinska, Simphiwe Zondi, Nobuhle Mthembu, Saiqa Mullick, Emma Ottolenghi, Immo Kleinschmidt, Susan E. Adamchak, Barbara Janowitz, and Carmen Cuthbertson. 2004. "Involving men in maternity care: South Africa," FRONTIERS Final Report. Washington, DC: Population Council. 


\section{Authors}

Busi Kunene, Mags Beksinska, Simphiwe Zondi, Nobuhle Mthembu, Saiqa Mullick, Emma Ottolenghi, Immo Kleinschmidt, Susan E. Adamchak, Barbara Janowitz, and Carmen Cuthbertson 


\title{
InVOlving Men In MATERnity CARE South Africa
}

\author{
October 2004
}

Reproductive Health Research Unit (Durban), Department of Obstetrics and Gynecology, University of the Witwatersrand

Busi Kunene, Mags Beksinska, Simphiwe Zondi, Nobuhle Mthembu

Population Council, Frontiers in Reproductive Health Program

Saiqa Mullick, Emma Ottolenghi

Family Health International

Immo Kleinschmidt, Susan Adamchak, Barbara Janowitz, Carmen Cuthbertson

This study was funded by the U.S. AGENCY FOR INTERNATIONAL

DEVELOPMENT (USAID) under the terms of Cooperative Agreement Number HRNA-00-98-00012-00 and Population Council Subagreement AI99.43A. The opinions expressed herein are those of the authors and do not necessarily reflect the views of USAID. 


\section{Executive summary}

In the current context of health care in South Africa, STIs and HIV/AIDS, as well as maternal mortality, partnered deliveries, and involving men in reproductive health, including PMTCT are important issues and priorities. Very little can be achieved for either mothers or infants unless reproductive health providers realize the need and take active steps toward involving men in reproductive health services.

The Reproductive Health Research Unit (RHRU) University of the Witwatersrand, in partnership with the FRONTIERS Program of the Population Council, and the KwaZulu Natal Department of Health conducted a three-year operations research study titled "Men in Maternity" (MIM) in the Ethekwini district. The study was completed in July 2003. A randomized cluster matched paired design was used with six clinics implementing the intervention and another six control clinics continuing to provide services following the current practices and guidelines of the Department of Health. Both rural and urban clinics were included.

The intervention was clinic-based and included two broad strategies: improving antenatal care services by strengthening the existing antenatal package and service monitoring and supervision; and introducing couple counseling by providing training to health providers, inviting partners of antenatal women to attend counseling twice during pregnancy and once post delivery, and providing information to couples with a new antenatal booklet.

At baseline 2082 women (1087 control and 995 intervention) and 584 male partners of the intervention women were interviewed using a structured questionnaire. A follow-up rate of 68 percent was achieved for women, and 80 percent of their partners were interviewed in both control and intervention sites. Analysis of baseline data showed that both control and intervention populations were similar in most variables measured by the study.

At follow-up few differences were found between the control and intervention groups to support the hypothesized effect of the intervention. Significant differences were found only in changing communication, partner assistance during pregnancy emergencies, and knowledge of the condom as a method of dual protection.

Although the intervention was intended for all couples in which the woman consented to have her partner participate, not all partners were exposed to the couple counseling intervention. Nevertheless, all participants who were interviewed post-intervention were included in the analysis, regardless of actual exposure to the intervention; therefore, positive effects among men exposed to counseling may have been diluted by those who were not. All women, regardless of their attendance at couple counseling, were exposed to the strengthened clinical service package in the intervention sites. The hospital where most women deliver and laboratory services were the same for both control and intervention groups would therefore have been equal in exposure to experience of delivery and postpartum initiation of family planning. The same supervisors and managers visited both intervention and control clinics, and there may have been some contamination in terms of improved service delivery.

Involving Men in Maternity Care

ii 
The intervention may be considered successful in demonstrating that male participation in this context is feasible. At least one-third of couples took the opportunity to attend the counseling. This is a positive outcome, given that this was a very new concept in a community where there was negligible male participation in maternity care and most couples were not cohabiting. Some men expressed willingness to participate, but were unable to due to employment schedules that conflicted with clinic hours of operation, inability to obtain permission from employers, or not being told of the counseling by their partners. The antenatal booklet was given to the most women and a high proportion shared the booklet with their partners. The response to the booklet was very positive from all those who read it.

In conclusion, the intervention was feasible, relevant and effective in significantly changing communication, partner assistance during emergency, condoms as a dual protection method, condom use, and condom use in last sexual encounter. Had the intervention been in place for a longer period or supported by mass communication efforts to encourage men to come to the clinic, we may have seen a much greater impact. 


\section{ABBREVIATIONS}

$\begin{array}{ll}\text { AIDS } & \text { Acquired Immune Deficiency Syndrome } \\ \text { ANC } & \text { Antenatal Care } \\ \text { DfID } & \text { Department for International Development } \\ \text { DOH } & \text { Department of Health } \\ \text { EC } & \text { Emergency Contraception } \\ \text { FC } & \text { Female Condom } \\ \text { FP } & \text { Family Planning } \\ \text { GEE } & \text { Generalized Estimated Equations } \\ \text { HIV } & \text { Human Immunodeficiency Virus } \\ \text { IEC } & \text { Information Education and Communication } \\ \text { KZN } & \text { KwaZulu Natal } \\ \text { MCH } & \text { Maternal and Child Health } \\ \text { MiM } & \text { Men in Maternity Project } \\ \text { NDOH } & \text { National Department of Health } \\ \text { OC } & \text { Oral Contraceptives } \\ \text { PMTCT } & \text { Preventing Mother to Child Transmission } \\ \text { PMMH } & \text { Prince Mshiyeni Memorial Hospital } \\ \text { RH } & \text { Reproductive Health } \\ \text { RHRU } & \text { Reproductive Health Research Unit } \\ \text { SADHA } & \text { South Africa Demographic and Health Survey } \\ \text { STI } & \text { Sexually Transmitted Infection(s) } \\ \text { USAID } & \text { United States Agency for International Development } \\ \text { WHO } & \text { World Health Organization } \\ & \end{array}$




\section{ACKNOWLEDGEMENTS}

We would like to acknowledge the following individuals and organizations for their assistance and support in this study. The Department of Health KwaZulu Natal, Maternal and Child Health, Ilembe Health Region, Prince Mshiyeni Memorial Hospital and clinics actively participated in the study. From these organizations we thank in particular Noel Philips, Irmeli Arselo, Janet Dalton, Dr. Badal, Mrs. Hadebe, Mrs. Shandu, Dr. Newman, the Community Medical superintendent of Prince Mshiyeni, and all Community Health Supervisors. Special thanks go to DRA for assisting in data entry as well as the fieldworkers who conducted the community survey component of the study. The provincial maternal task team provided input to the antenatal handbook, and Melanie Pleaner assisted in its development.

We are grateful to USAID for financial assistance to the study. Additional funding was provided by the Department for International Development (DfID) for IEC materials.

We thank our colleagues at the Population Council and Family Health International for their guidance, technical support, and comments on draft reports.

Finally, we would like to thank staff in all the intervention clinics that supported the programme, in particular the couple counselling, and were so giving of their time. A special thanks is offered to all the men and women who participated in the project. 


\section{TABLE OF CONTENTS}

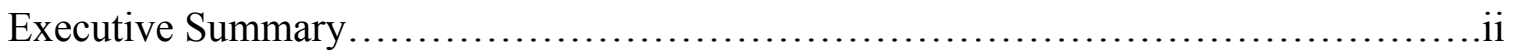

Abbreviations.................................................................

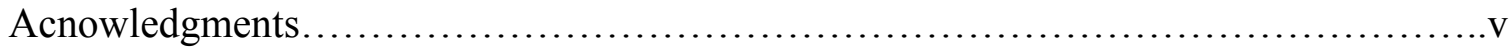

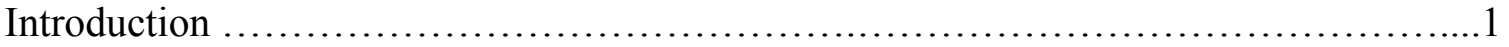

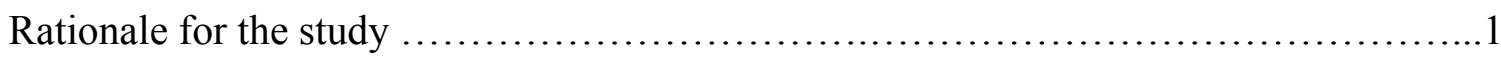

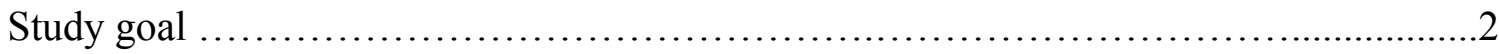

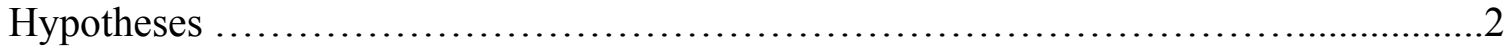

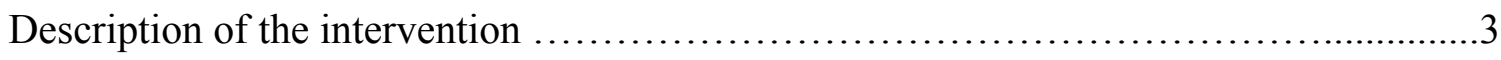

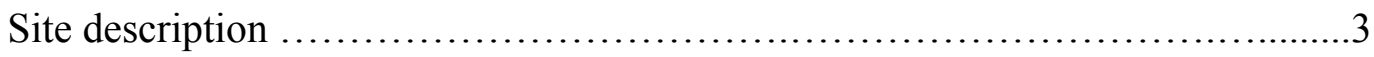

Activities undertaken to implement the intervention ...........................

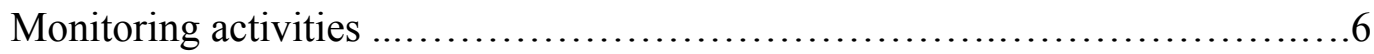

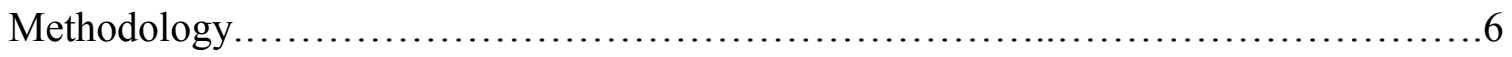

Study design..........................................................

Sample size......................................................6

Target population and inclusion criteria...................................

Data collection.........................................................

Data management and analysis........................................ 8

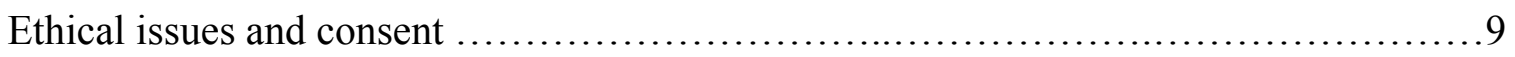

Risks and benefits.................................................9

Confidentiality...................................................... 9

Compensation.................................................... 10

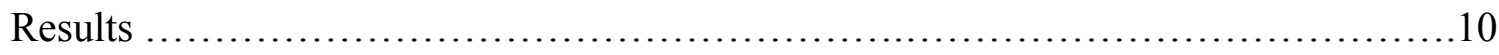

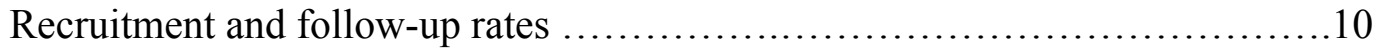

Comparison of the study groups at baseline ..............................11

Exposure to the intervention......................................... 14

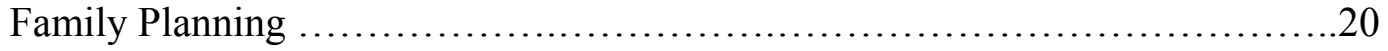

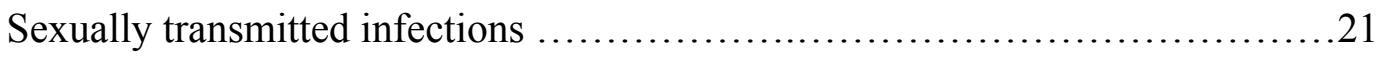

Dual protection knowledge .........................................23

Male involvement, support and communication ..........................24 
Knowledge of danger signs, problems experienced during pregnancy, and action

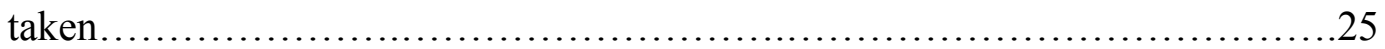

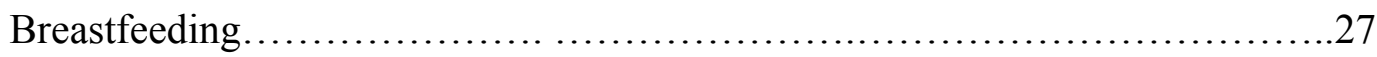

Client and provider satisfaction with the intervention.......................28

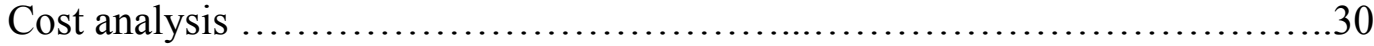

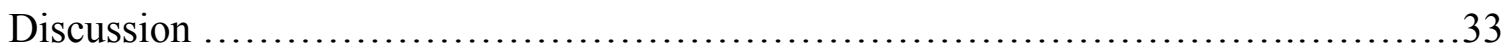

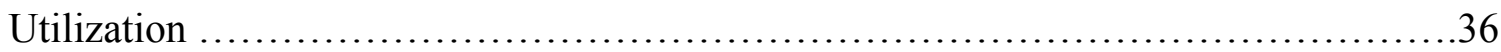

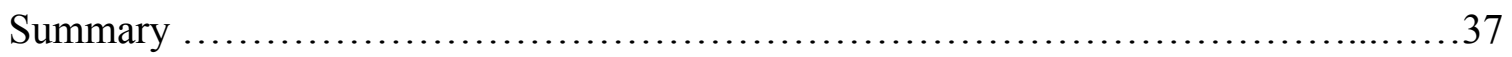

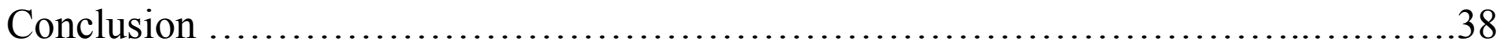

References........................................................................ 40

\section{Appendices}

Appendix 1. Materials and tools developed for the study .......................42

Appendix 2. Data sources, methods, and sample sizes for study...................43

Appendix 3. Distribution of client load per day...............................44

Appendix 4. Summary of main indicators at follow-up by clinic.................. 45

Appendix 5. Conference presentations.....................................46 


\section{List of Tables and Figures}

Table 1. Follow-up rate at six months postpartum...............................10

Table 2. Reasons for loss to follow-up ........................................ 10

Table 3. Socio-demographic characteristics of participants in intervention and

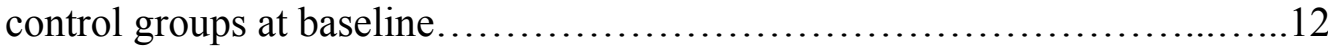

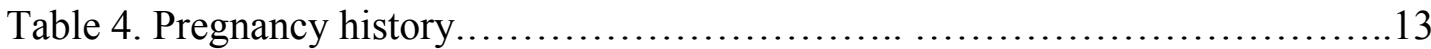

Table 5. Percent of study participants aware of counseling and attending

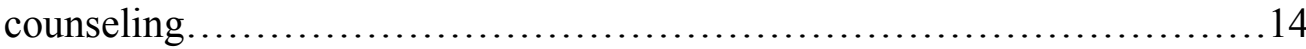

Table 6. Percent of women and men reporting exposure to antenatal care booklet....15

Table 7. Percent of consultations in which providers discussed various topics during exams for ANC clients in the posttest.................................... 18

Table 8. Association of various factors that explain differences in the length of contacts (in seconds) for exams .......................................... 18

Table 9. Percent of group talks in which various topics were discussed by group......19

Table 10. Current method use by sexually active women at six months postpartum. 20

Table 11. Percent of women and men reporting knowledge of STI pre- and post-

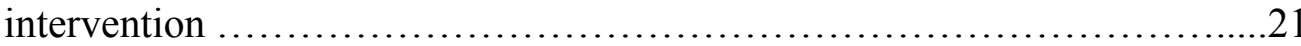

Table 12. Prevalence of risky behavior and condom use by male partners.............22

Table 13. Syphilis testing and management among women ........................23

Table 14. Percent of women and men knowing uses of condoms .....................23

Table 15. Issues discussed by matched couples...................................24

Table 16. Women's report of partners' involvement during labor ....................24

Table 17. Knowledge of danger signs during pregnancy ................................

Table 18. Percent of women experiencing danger signs during index pregnancy

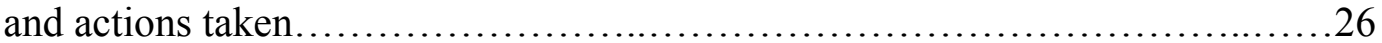

Table 19. Percent distribution of pregnancy outcomes...........................27

Table 20. Breast feeding practices.................................................... 28

Table 21. Activities and resources used during the intervention .....................30

Table 22. Financial and non-financial costs of three phases intervention (ZAR).....31

Table 23. Total costs, cost per clinic and cost per couple counseled by

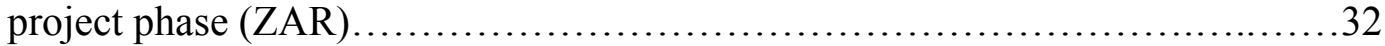


Figure 1. Reasons given by women why couple counseling was helpful..............14

Figure 2. Reasons given by men why couple counseling was helpful................15

Figure 3. Number of couples counseled per month.............................16 


\section{INTRODUCTION}

The 1998 South Africa Demographic and Health Survey reported high utilization (94\%) of antenatal care by pregnant women. ${ }^{1}$ Although sexually transmitted infections (STIs) are a major public health problem, pregnant women rarely receive information on this topic. The limited information given by health providers on reproductive health including STIs and condom use is primarily aimed at women, yet they are not financially or culturally positioned to make decisions about these issues. In addition, women are often not in a position to talk about sex or condom use with their partners, yet they are often expected to modify risk behavior for STIs which, in most cases, cannot be done without some degree of partner involvement. It is becoming increasingly clear that every pregnancy in South Africa faces an element of risk, because men, as partners and decision makers, are not informed about reproductive health issues.

\section{RATIONALE FOR THE STUDY}

Men generally do not accompany their partners to family planning, antenatal or postnatal care services and would not be expected to attend the labor or birth of their child. In addition, men are rarely exposed to clinic reproductive health services as they often seek care for STIs in the private sector and condoms can be obtained from clinics without contact with providers. The issue of accessibility of reproductive health $(\mathrm{RH})$ services to men in South Africa is a logistical and cultural problem. The exclusive use of services by women has to a great extent made RH services unfriendly for men. The need for integration of these services (i.e., antenatal, STI, family planning and male involvement) seems both appropriate and timely.

Traditionally, couples and providers alike have considered family planning (FP) a woman's issue. Despite this, perceptions abound of men as barriers in decisions on whether to use methods, when to adopt use and which methods best suit the couple's needs. However, recent research shows that not only do women want their male partners to be more actively involved, but also men themselves are more interested than previously believed. Men are becoming more aware of their critical role in reproductive health. ${ }^{2}$ Nevertheless, most programs have not been successful in involving men in making more equitable and collaborative reproductive health decisions for couples, and providing them with both the essential information and skills for this to happen. In addition, health care providers in the public sector have limited skills to implement male friendly services particularly in the area of maternity care and family planning. In South Africa, the lack of services designed to involve men in fertility regulation or reproductive choice was identified in 1994 in an assessment of reproductive health services. ${ }^{3}$ Tsui et al. (1997) state that, with respect to obstetric care, it is often families, and not the woman alone, who make decisions. ${ }^{4}$ They further stress that men are the obvious target audience because in many cases they control the cash reserves or their permission needs to be obtained for obstetric care-seeking. ${ }^{4}$ Men may also be seen as the principal vectors of their partner's sexual health regarding STIs. Not uncommonly, women who perceive themselves to be in a monogamous relationship are at risk of infection because of their partners' sexual behaviours. 5

Involving Men in Maternity Care 
In addressing men's involvement in reproductive health, it is important to consider how to frame their contact with the health system so that it will encourage their future and continued involvement. The rationale behind choosing the pre- and post-natal periods as good times to encourage male participation is that evidence suggests that men may be more interested in their partners' well-being than is usually the case because of their shared role in producing a healthy child. ${ }^{6}$ Research also indicates that men themselves, as well as their partners, would prefer that they play a more active role during pregnancy, delivery and infant care, but that societal and health system norms often mitigate against this. ${ }^{7}$ Unpublished data from the focus groups discussions conducted during the planning phase of the study reported here indicate that some of the nurses as well as women clients were concerned about male involvement, as culturally men were not expected to participate in maternity issues. This finding was not unexpected as in this traditional Zulu community men have not been welcomed in antenatal clinics in the public sector. The structure of antenatal clinics in the public sector does not promote attendance as a couple, and this is further reinforced by a provincial policy guideline that suggests that women should be attended in groups. ${ }^{8}$

\section{STUDY GOAL}

The main goal of the study was to design and test an expanded antenatal and postpartum care program aimed at improving women's and men's reproductive health, particularly by increasing the use of appropriate postpartum family planning and STI and HIV/AIDS protective behaviors.

\section{Research questions}

The study sought to address the following research questions.

1. Will men be willing, when invited, to accompany their partners to a coupleoriented program during their antenatal and postpartum care?

2. Will the intervention be effective in increasing family planning knowledge and use, STI knowledge and prevention, couple communication and male involvement, recognition of pregnancy danger signs, and mother and baby's health care at six months postpartum?

3. Will the intervention be cost-effective, acceptable, and feasible in the public health service?

\section{HYPOTHESES}

The following hypotheses were tested:

1. Exposure to the intervention will have a positive impact on men and women's use of family planning at six months postpartum. 
2. Exposure to the intervention will have a positive effect on men and women's STI knowledge and preventive behaviors at six months postpartum.

3. Exposure to the intervention will increase clients' knowledge of dual protection provided by condoms (i.e., protection from STIs and unwanted pregnancy).

4. Exposure to the intervention will have positive effects on inter-spousal communication and support on reproductive health matters.

5. Exposure to the intervention will have positive effects on selected indicators of infant health, particularly exclusive baby feeding practices.

6. Exposure to the intervention will have positive effects on clients' and providers' satisfaction with antenatal and postnatal care services.

7. The experimental intervention will produce the hypothesized results in a cost effective manner; both in terms of its marginal and total cost as well as any additional opportunity cost that are incurred for the new services.

\section{DESCRIPTION OF THE INTERVENTION}

The intervention consisted of two components:

1. improving existing antenatal care services including information, education, communication and dissemination of an information leaflet and a booklet for couples to read and discuss ("Ukuba umzali"); and

2. introducing strengthened counseling for pregnant women and their partners, through individual and group couple counseling.

Men were invited to participate in three counseling sessions through the maternity period. Two of these counseling visits were to take place during pregnancy and one at six weeks post delivery.

\section{Site description}

The study was conducted in KwaZulu-Natal (KZN) Province in South Africa. The province has a population of 9.1 million people, with over half (57\%) living in rural areas. ${ }^{10}$ The literacy rate for the province was reported as 89 percent which is above the national rate of 85 percent $^{11}$. Eighty-one percent of the population is African, mainly Zulu, with strong cultural beliefs about the role of men in antenatal and postnatal care. Men are not expected to be involved in maternity related issues with some believing that a man will become weak if he is present at the birth of his baby. The HIV prevalence among antenatal clients in KZN was 33.5 percent in $2002^{12}$ and the maternal mortality rate increased from 188/100 000 in 1998 to 243/100 000 in 2001, with 23 percent of these deaths being HIV related ${ }^{13}$.

The study was conducted in eight urban and four rural clinics in the catchment area of Prince Mshiyeni Memorial Hospital (PMMH). This tertiary hospital has 22 clinics under 
its administration, almost all providing antenatal care services. Since 1992, due to political unrest and security issues, the clinics have discontinued birthing services and today most women deliver in the hospital, which now attends 12,000 deliveries per year. Prince Mshiyeni Memorial Hospital is located in Umlazi Township, which, with a population of about two million, is the largest township in the Durban metropolitan area and the second largest township in South Africa.

Clinic ANC services are delivered by registered nurse-midwives with doctors only available at the hospital. Syphilis screening is mandatory for all antenatal care clients; samples are sent from the clinics to the hospital for testing and results returned to the clinics. The service, which is mandatory, is well established; however, it is presented with a number of challenges. These include: lack of transport for blood specimens to be taken to the laboratory; poor treatment compliance; low rates of partner tracing and treatment; late presentation of pregnant women; and long turn around time from taking blood samples to receiving results. ${ }^{14}$

\section{Activities undertaken to implement the intervention}

\section{Ensuring clinic management and staff commitment to the study}

Several buy-in meetings and workshops regarding the aims and objectives of the study were undertaken with key stakeholders starting in September 2000. These included Department of Health (DOH) officials at local, provincial and national levels, as well as clinic managers and health care providers. Several technical working groups were tasked to develop information, education and communication (IEC) materials, in-service training modules, and to make recommendations for a couple-friendly environment. The DOH made trainers and staff available for the IEC and training module development.

\section{Formative research}

This study was a clinic-based intervention and therefore there was a need to understand how the clinics functioned prior to implementation. Formative research was undertaken to inform the planned intervention. This included a wide range of activities: facility-based analysis; a case study on syphilis screening and management in antenatal clients; client flow analysis and a time motion study describing how providers spent their time; focus group discussions; and record reviews.

Formative research findings documented a lack of ANC guidelines and protocols, inadequate essential equipment, and a shortage of drugs required for routine pregnancy care and STI management. The management information system was inadequate and IEC materials focusing on pregnancy were lacking. Most providers were not assessing, educating or counseling clients on STIs and HIV/AIDS. In many clinics, congestion was compromising clients' privacy during consultations. Client flow and time motion studies conducted at the outset of the study showed that most of the clients were attending clinics in the morning and there was time in the afternoon when couple counseling could be scheduled (see Appendix 3). 


\section{Training}

Two types of training were conducted in the intervention clinics. Whole site training was given to all staff including support staff such as general assistants and clerks. The aim of this training was to familiarize staff about the project and to address any concerns. The second component of training was more intensive and aimed at the 65 professional nurses working in the intervention clinics. During a week-long training workshop they were exposed to a variety of topics, including: pregnancy, preparation for delivery, postnatal care, involving men in maternity, sexual health, basic counseling, quality improvement and infection control. These training workshops were held between February and March 2001. In addition, training of trainers was conducted to ensure that the training team in the area was familiar with all the issues pertaining to the intervention.

\section{Clinic upgrading}

A number of activities were conducted to enable the new package of services to be implemented. Many clinics reported lack of or defective equipment. Some clinics had problems with bathrooms for clients. These were addressed either through liaison with the department to access equipment for the clinics or the study covered the cost of some repair work.

\section{Counseling}

Each clinic developed its own plan to conduct couple counseling. Four clinics chose to utilize less busy afternoons to schedule group counseling, one clinic preferred two mornings per week and one that was already conducting antenatal care daily chose to fit couple counseling in their daily schedule. The counseling content was as follows: antenatal care procedures, physiological and emotional changes, pregnancy danger signs and care seeking, delivery plan, post delivery care for mother and baby, sexually transmitted infections, including HIV/AIDS prevention and management, family planning and exclusive infant feeding. Guidance was given during training on the content and duration of each counseling session. Most clinics developed their own posters with these topics highlighted for easy reference.

\section{Encouraging male involvement}

In order to facilitate involvement of men, invitation letters to male partners were made available to women, regardless whether they were recruited into the study. Leaflets were also developed that informed participants and their partners of the study. In addition, attendance certificates to give to employers were developed for men wishing to attend the couple counseling during their working hours.

Once women consented to participate, they were given letters inviting both themselves and their partners to come to the clinic and attend three counseling sessions (two during antenatal care and one at six weeks post delivery). The counseling sessions were conducted in groups, as time constraints for staff were such that individual couple counseling could not be done. Sessions were conducted by staff members (registered or enrolled nurses) who were trained in male involvement, and were designed to be interactive and involve two-way discussions. The number of participants, content of the discussions, and comments were recorded on a special register developed for the study. Participants were encouraged to speak to the health providers after the session if any 
issues needed to be discussed privately. Women whose partners were not able to attend were still encouraged to attend the counseling sessions.

Women were given an antenatal care booklet that reinforced the information given in the counseling. They were asked to read the book and share the information at home with their partners.

\section{Monitoring activities}

\section{Strengthened supervision}

Continuous support and mentoring was given by both the district trainer and RHRU staff to ensure that providers adapted to their new practices at their facilities until competency was gained and a minimum quality of service was achieved. A supervisory tool was developed and used to regularly monitor both practice and record keeping and to facilitate follow-up and supportive supervision. The intervention clinics were visited monthly for the first six months, bimonthly for the second six months and every three months thereafter until the study was completed after 18 months. Observation of the clinic structure, rendering of services and couple counseling were conducted during these visits. Progress of the intervention and problems identified were discussed with the clinic staff. Clinic supervisors meetings were held to provide a platform for sharing lessons learned from individual clinics and peer support.

\section{Management information system}

Management information was collected using a modified version of the existing antenatal care register used in clinics and a counseling register was also developed; information was recorded on the number of clients counseled, topics discussed, and the job title or position of the person who conducted the counseling session.

\section{METHODOLOGY}

\section{Study design}

The study design used was a cluster randomized controlled trial with six clinics implementing the intervention and another six continuing to provide services following the current practices and guidelines as recommended by the Department of Health (control). Both rural and urban clinics were included. The size of the clinics varied considerably with some clinics seeing as many as 185 first time antenatal clients and some as few as 20 clients per month. Clinics were matched by size and rural/urban status, before being randomly allocated as intervention or control sites.

\section{Sample size}

Among the key variables described, the most important in terms of drawing conclusions about the effectiveness of the intervention was assumed to be prevalence of contraceptive use by women at six months postpartum, and so was used to determine sample size. The baseline level of contraceptive use at six months postpartum for this population was not known, so the sample size calculation was based on the contraceptive prevalence rate of 55 percent among all women in KwaZulu Natal reported in the 1998 SADHS. 
- The number of clinics participating in the study was limited to twelve for logistic and budgetary reasons. The study was intended to have 80 percent power to demonstrate a significant effect of the intervention (at the customary five percent two-tailed significance level) if the true difference in contraceptive use at six months postpartum between intervention and control clinics was at least 15 percent. This would require a sample of 130 women per clinic. ${ }^{13}$ A coefficient of variation of 0.1 between pairs of clinics was assumed. Allowing for 20 percent loss to follow-up, the required sample size per group was 936.

\section{Target population and inclusion criteria}

All women who attended the antenatal care clinics for one of their early prenatal visits from June to September 2001 in the control clinics and from October 2001 to February 2002 in the intervention clinics were approached for an interview. Only those who met the following criteria were recruited:

- Pregnant between 10 and 30 weeks of gestation;

- Living with a partner or in a regular visiting relationship ${ }^{i}$ for more that one year and expecting the partner to be present during and after the pregnancy;

- Living in the area for at least one year and planning to stay in the area for at least six months post delivery; and

- Consenting to be recruited into the study and to have her husband or partner contacted for participation and/or interview at 6 months postpartum.

Male partners were recruited if they met the following criteria:

- Permission given by the pregnant woman to contact him and ask for his participation; and

- Consenting to be interviewed at baseline (intervention group only) and at six months postpartum (both intervention and comparison groups).

\section{Data Collection}

\section{Interviews}

Data to evaluate the intervention were collected through individual interviews with the samples of women and their male partners in both the control and experimental groups. Baseline interviews undertaken when recruiting women in both the control and experimental groups took place at the clinic immediately before the woman had commenced her first antenatal visit. Arrangements were made with the clinic staff to delay group health education, normally given prior to receiving any other antenatal care services, to accommodate the recruitment. This was because the first visit formed part of the intervention and so the women were interviewed before exposure to the intervention. Male partners of intervention clinic women who consented to have their partners

\footnotetext{
i A "regular visiting relationship" is one in which the couple is not cohabiting but see each other on a routine basis; it is often, but not always, a monogamous relationship. 
involved were either interviewed on the same day or invited to come with their partners for the following antenatal visit. If unable to come to the clinic they were interviewed at their places of residence, usually at the weekend. Follow-up interviews were conducted six months after delivery. These interviews were normally conducted at places of residence, and men and women were interviewed separately.

\section{Focus group discussions}

Towards the end of the project, focus group discussions were conducted with health providers at the intervention clinics in order to evaluate their satisfaction with the new way of providing services.

\section{Cost data}

Data collection spreadsheets were designed to collect the costs of planning, implementing, and carrying out the service delivery and monitoring associated with the intervention. These spreadsheets covered the various activities included in each of the phases of the intervention. For each activity the resources used to conduct the activity were identified, the amount of each of the resources used were measured, and its unit cost calculated. The amount of each resource used was multiplied by its unit cost and summed to obtain the total costs of the activity. The cost analysis was undertaken from the perspective of the implementing organizations. The focus was thus on the costs incurred by these organizations to carry out project activities. The opportunity cost of all resources used was included regardless of whether the project made a financial payment to obtain them. Thus, for example, the cost of the time of trainees was included, as they had to take time away from work in order to attend training sessions. The cost of research to evaluate the intervention was excluded, but the costs of formative research used to design the intervention were not. The cost analysis is an important tool to inform policy decision-makers about the feasibility and cost of scaling up the intervention once it was completed.

\section{Data management and analysis}

All data collectors were supervised on a regular basis. Unscheduled supervision visits were made to ensure that the interviewers were following pre-defined protocols and ethical guidelines. A research assistant and the coordinator were responsible for checking data collection quality and ensuring that data were stored in a safe and confidential place. The research assistant checked the data collected from interviews before data entry. At least five percent of the questionnaires were validated each month by a research assistant and the coordinator by visiting the interviewee with the field workers or making a call. Identifying information was kept separately in a secure place and was only used to facilitate the follow-up of couples at six months postpartum.

Questionnaires were sent to Development Research Africa (DRA) for data entry. All data were double entered. Data cleaning involved the identification of missing data, range and distribution checks, as well as checking the coherence of data within each case. Focus group discussion tapes and documents were transcribed and analysis was done manually.

Individual interview responses were cross-tabulated and percentages calculated to compare control and intervention groups. Responses were aggregated by clinic, and 
significance tests were performed on the clinic-level data using Student's t-test with the clinic as the unit of analysis, to allow for the cluster randomization of the study design.

\section{ETHICAL ISSUES AND CONSENT}

\section{Risks and benefits}

Subjects were not required to undergo any physically invasive procedures as part of the research beyond those mandated by the national norms for their antenatal care, i.e., undergoing a physical exam and collecting blood and urine for a syphilis test and protein/glucose tests respectively. Drugs used for treatment of syphilis and sexually transmitted diseases are those specified in national guidelines.

It was anticipated that sensitive topics discussed with the clinical provider or research interviewer might cause distress in some clients or their partners. There was also concern that there might be some risk of physical, emotional or sexual abuse from women's participation in the intervention, especially if their partners opposed their participation in the study. Both clinical providers and interviewers were trained to inquire about distress and abuse in participants, provide support for coping with distress and provide rapid linkage to local domestic violence services.

The selection characteristics and training of the interviewers for this study were key to avoiding risks that might be posed to the client. Interviewers were made aware of the importance of minimizing subjects' level of anxiety or stress and of the absolute requirement of not divulging any information received from female participants to their male partners and vice-versa. Data collection training included focused discussions and exercises regarding the meaning and process of informed consent and the importance of protecting the privacy of the subjects and confidentiality of the information obtained from them. Only those trainees who exhibited sensitivity toward all of these issues were hired as data collectors for the study.

\section{Confidentiality}

Procedures to assure confidentiality were strictly observed. Identification code numbers were used on all interview forms to safeguard the data; no personal identifiers were recorded on the interview schedules or observation forms. All data were kept separately from identifying information and both were stored in locked files in the RHRU office. Access to the research data was limited to the research staff. Clinical staff was not able to access the data or share information obtained during the project by the research staff. Identifying information has not been disclosed in reports, presentations or publications.

As part of the Population Council's program for monitoring the quality of research, every subject was asked to acknowledge the possibility that an interview may be requested by a representative of the Population Council to determine whether informed consent was given. If an interview was requested, the subject had the option of accepting or declining the interview. 


\section{Compensation}

Participants in the study were not paid to participate, nor were they otherwise compensated beyond reimbursement for transportation expenses if they chose to be interviewed at a site that was not their home.

\section{RESULTS}

\section{Recruitment and follow-up rates}

At baseline a total of 2082 women, (1081 control and 995 intervention), were interviewed using a structured questionnaire (Table 1). Male partners were only interviewed in the intervention sites at baseline provided the female participant agreed to have her partner involved. Ninety-nine percent of women who qualified to participate in the study gave consent and agreed to have their partners involved. However, only 59 percent (584) of male partners of intervention women were interviewed; the remainder could not be located, refused, or were unable to take time from their employment for the interview.

A follow-up rate of 64 percent $(n=694)$ of the control women and 73 percent $(n=729)$ of the intervention women was achieved at six months postpartum. Of the male partners, 558 control and 608 intervention men were interviewed at six months postpartum. Some men in the intervention site who were not interviewed at baseline were located and interviewed at six months postpartum.

Table 1. Follow-up rate at six months postpartum

\begin{tabular}{|l|c|c|c|c|}
\hline Site & \multicolumn{2}{|c|}{ Baseline } & \multicolumn{2}{c|}{ Follow-up } \\
\hline & Female & Male & Female & Male \\
\hline Control & 1081 & 0 & 694 & 558 \\
\hline Intervention & 995 & 584 & 729 & 608 \\
\hline
\end{tabular}

Reasons for loss to follow-up included participants changing residence or giving incorrect addresses in order to be accommodated at the clinic of their choice (Table 2).

Table 2. Reasons for loss to follow-up

\begin{tabular}{|l|c|c|c|c|}
\hline \multirow{2}{*}{ Reason } & \multicolumn{2}{|c|}{$\begin{array}{c}\text { Control } \\
\text { (n=1081) }\end{array}$} & \multicolumn{2}{c|}{$\begin{array}{c}\text { Intervention } \\
\text { (n=995) }\end{array}$} \\
\cline { 2 - 5 } & Women & Men & Women & Men \\
\hline Wrong address & 246 & 274 & 173 & 116 \\
\hline Change address & 68 & 123 & 42 & 98 \\
\hline Not willing & 58 & 105 & 39 & 83 \\
\hline Died & 8 & 7 & 9 & 9 \\
\hline Other & 7 & 14 & 3 & 5 \\
\hline Total & $\mathbf{3 8 4}$ & $\mathbf{5 2 3}$ & $\mathbf{2 6 6}$ & $\mathbf{3 1 1}$ \\
\hline
\end{tabular}




\section{Comparison of the study groups at baseline}

The characteristics of the control and intervention groups are shown in Table 3. The data presented on men consists of responses given by women about their partners for selected characteristics (i.e., age, education, literacy and employment status). Both female groups were similar in most background characteristics. The mean age of the women in the control group was 23 years (range 14-45) and slightly higher in the intervention group at 24 years (range 14-43). Characteristics of men were similar in both intervention and control groups. The mean age of the men in both intervention and control groups was 28 years although the range was wider in the intervention men (17-71) compared to control men (14-63).

\section{Relationship status}

Two-thirds of women in both control (66\%) and intervention (64\%) groups were in a regular "visiting" relationship but not living with the father of the child. Very few were married in either the control $(7 \%)$ or intervention (9\%) group.

\section{Education and literacy}

The majority of women in both groups could read English and a local language. Almost all could write. Three-quarters had completed come level of secondary school beyond basic primary education; 25 percent had completed secondary school (matric; data not shown). The majority had completed their primary education. Very few women had higher education (university, technikon, other). Less than one-sixth of the women were employed.

\section{Household resources}

Most homes had a radio and a television. Two-thirds (66\%) of control women had water inside the house compared to only half $(53 \%)$ of intervention women. Similarly control women were more likely to have an inside toilet (65\%) compared to intervention women $(49 \%)$. Most women used mini buses, run by private owners, locally called 'taxis', as their main form of transport (95\%). 
Table 3. Socio-demographic characteristics of participants in intervention and control groups at baseline

\begin{tabular}{|c|c|c|c|c|}
\hline \multirow[t]{2}{*}{ Characteristic } & \multicolumn{2}{|c|}{$\begin{array}{l}\text { Control \% } \\
(n=1081)\end{array}$} & \multicolumn{2}{|c|}{$\begin{array}{c}\text { Intervention \% } \\
(n=995)\end{array}$} \\
\hline & Women & Men & Women & Men \\
\hline \multicolumn{5}{|l|}{ Age } \\
\hline Less than 20 & 29 & 6 & 24 & 6 \\
\hline $20-29$ & 52 & 52 & 53 & 50 \\
\hline $30-39$ & 17 & 27 & 20 & 27 \\
\hline 40 and above & 1 & 9 & 2 & 10 \\
\hline Missing & $<1$ & 6 & $<1$ & 6 \\
\hline Mean age (years) & 23 & 28 & 24 & 28 \\
\hline \multicolumn{5}{|l|}{ Relationship status } \\
\hline Regular "visiting" relationship & 66 & & 64 & \\
\hline Not married, living together & 24 & & 26 & \\
\hline Married, living together & 7 & & 9 & \\
\hline Married, living apart & 1 & & 1 & \\
\hline Broken up / not together & 2 & & 0 & \\
\hline \multicolumn{5}{|c|}{ Highest completed level of education } \\
\hline No education & 2 & 2 & 2 & $<1$ \\
\hline Primary only (grade $1-7$ ) & 16 & 16 & 16 & 6 \\
\hline Secondary (grade 8-12) & 78 & 71 & 77 & 79 \\
\hline $\begin{array}{l}\text { Post matric (university, } \\
\text { technikon) }\end{array}$ & 4 & 7 & 5 & 7 \\
\hline Missing / do not know & & 4 & & 7 \\
\hline \multicolumn{5}{|l|}{ Literacy } \\
\hline Writes & 99 & 97 & 97 & 97 \\
\hline Reads local language & 97 & 96 & 95 & 96 \\
\hline Reads English & 85 & 92 & 78 & 87 \\
\hline \multicolumn{5}{|l|}{ Employment Status } \\
\hline Unemployed & 86 & 18 & 87 & 21 \\
\hline Employed full or part time & 14 & 82 & 13 & 79 \\
\hline \multicolumn{5}{|l|}{ Household resources } \\
\hline Electricity & 88 & & 80 & \\
\hline Water inside & 66 & & 53 & \\
\hline Toilet inside & 65 & & 49 & \\
\hline Telephone & 36 & & 31 & \\
\hline \multicolumn{5}{|l|}{ Access to media } \\
\hline Radio & 89 & & 87 & \\
\hline Television & 77 & & 69 & \\
\hline \multicolumn{5}{|c|}{$\begin{array}{l}\text { Means of transport commonly } \\
\text { used to come to clinic }\end{array}$} \\
\hline Taxi & 95 & & 95 & \\
\hline Own car & 4 & & 3 & \\
\hline Bus & 45 & & 42 & \\
\hline Train & 25 & & 19 & \\
\hline Walk & 51 & & 55 & \\
\hline
\end{tabular}




\section{Pregnancy history at baseline}

Almost half of the participants were pregnant for the first time. In general, pregnancy history was similar in the intervention and control groups except with respect to gestational age. Almost half (48\%) of the control women but a smaller proportion of the intervention women (35\%) were between six and seven months into their pregnancy at first ANC visit. This was significantly different and resulted from a change in inclusion criteria at recruitment.

Table 4. Pregnancy History

\begin{tabular}{|c|c|c|}
\hline Pregnancy history & $\begin{array}{c}\text { Control women \% } \\
(n=1081)\end{array}$ & $\begin{array}{c}\begin{array}{c}\text { Intervention women } \% \\
(n=995)\end{array} \\
\end{array}$ \\
\hline \multicolumn{3}{|r|}{ 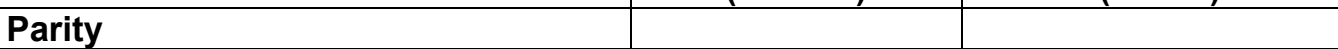 } \\
\hline 0 & 46 & 43 \\
\hline 1 & 27 & 28 \\
\hline 2 & 15 & 14 \\
\hline 3 or more & 11 & 14 \\
\hline \multicolumn{3}{|l|}{ Number of sons } \\
\hline 0 & 67 & 64 \\
\hline 1 & 24 & 25 \\
\hline 2 & 7 & 8 \\
\hline 3 or more & 2 & 2 \\
\hline \multicolumn{3}{|l|}{ Number of daughters } \\
\hline 0 & 70 & 69 \\
\hline 1 & 23 & 21 \\
\hline 2 & 6 & 8 \\
\hline 3 or more & $<1$ & $<1$ \\
\hline \multicolumn{3}{|c|}{ Months gestation at $1^{\text {st }}$ ANC visit } \\
\hline $2-3$ & 9 & 12 \\
\hline $4-5$ & 42 & 52 \\
\hline $6-7$ & 48 & 35 \\
\hline Mean gestational age & 5.2 & 4.9 \\
\hline \multicolumn{3}{|c|}{ Pregnancy not resulting in live birth* } \\
\hline Yes & 14 & 14 \\
\hline No & 86 & 86 \\
\hline Babies stillborn & $(n=155)$ & $(n=142)$ \\
\hline Yes & 72 & 70 \\
\hline No & 28 & 30 \\
\hline
\end{tabular}

${ }^{*}$ Not resulting in live birth means abortion, miscarriage or stillbirth .

The women in both intervention and control groups were thus comparable in sociodemographic and obstetric characteristics. Characteristics of male partners reported by women were also comparable in the two groups. In light of baseline equivalence, the data shown in all the following tables in this report are based on the six month follow-up data for both men and women. 


\section{Exposure to the intervention}

\section{Couple counseling}

Clinic registers showed that a total of 542 couples were counseled across all six clinics during the intervention between June 2001 and October 2002 (17 months). Thirty-four percent of those who attended the clinics had been recruited into the study. All women attending antenatal care in the intervention clinics were given similar information, during their antenatal care health education, to that given during couple counseling. The results in Table 5 show that 80 percent of women were aware of couple counseling and most invited their partner. About half of the women who invited their partner attended counseling, nearly equally divided between those who went with their partner and those who went along. However, less than half the men invited came to a counseling session, with or without their partner. Tables 5 and 6 (see below) highlight the fact that women and men in the intervention groups were not all fully exposed to the intervention. This would dilute the effect of the intervention and tend to underestimate its overall potential impact.

Table 5. Percent of study participants aware of counseling and attending counseling

\begin{tabular}{|l|c|c|}
\hline & $\begin{array}{c}\text { Intervention } \\
\text { women \% } \\
(\mathbf{n}=\mathbf{7 2 1})\end{array}$ & $\begin{array}{c}\text { Intervention } \\
\text { men \% } \\
(\mathbf{n}=6 \mathbf{6 0 1})\end{array}$ \\
\hline Aware of couple counseling & 76 & $71^{11}$ \\
\hline $\begin{array}{l}\text { Invited partner / invited by partner for couple } \\
\text { counseling }\end{array}$ & 70 & 78 \\
\hline Attended couple counseling with partner & $23(\mathrm{n}=506)$ & $27(\mathrm{n}=470)$ \\
\hline Attended couple counseling without partner & $22(\mathrm{n}=506)$ & $2(\mathrm{n}=470)$ \\
\hline
\end{tabular}

Almost all (98\%) women who attended couple counseling with their partners said it was helpful and cited the reasons (see Figure 1.). A third of women who attended couple counseling with their partners reported that their partner was more helpful and supportive after attending counseling.

Figure 1. Reasons given by women why couple counseling was helpful

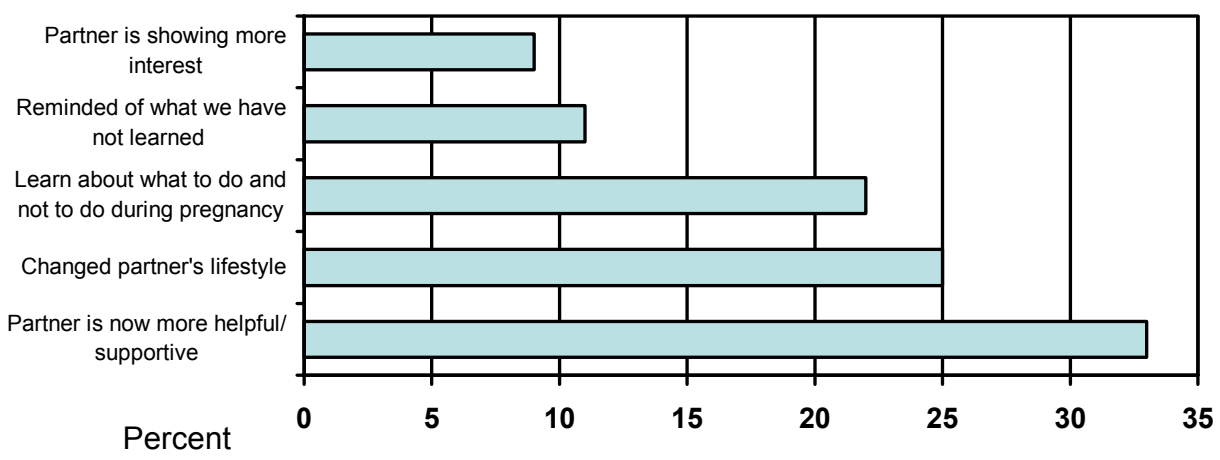

\footnotetext{
ii The discrepancy between those aware of counseling and those invited reflects the Zulu translation of "aware", implying that men knew about the counseling but were not aware of its specific content because they had not yet attended, or they were not aware of the counseling service prior to having been invited.
} 
More than two-thirds of the men who attended couple counseling said the information gained during counseling had been useful.

Figure 2. Reasons given by men why couple counselling was helpful

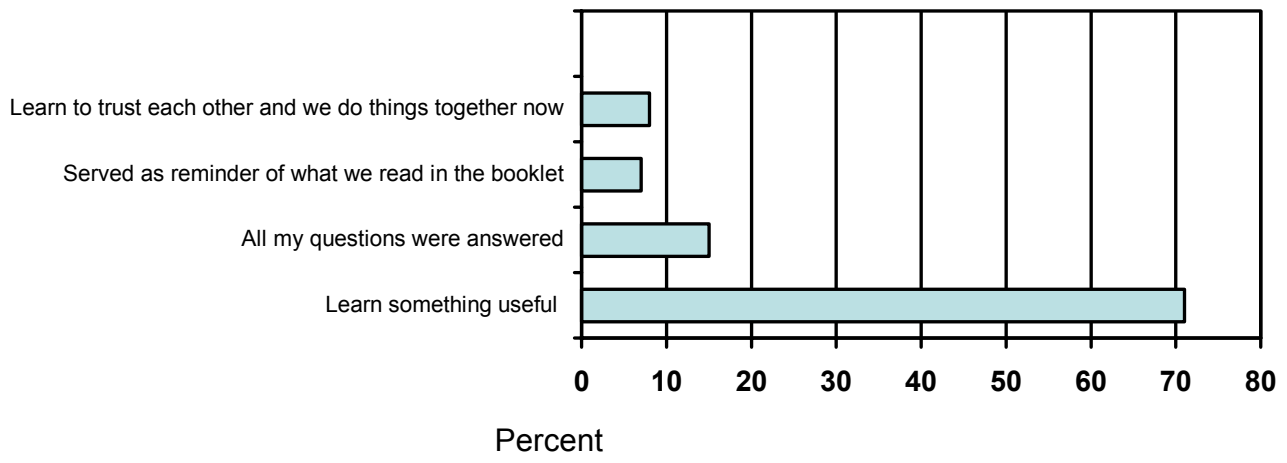

\section{Information and education materials}

The ANC booklet called "Ukuba umzali" was intended to be given to women at their first antenatal care visit and women were encouraged to read it and share this with their partners (Table 6). Although the clinics all agreed to distribute the booklet to every women in the intervention, one clinic in particular did not comply and this resulted in only two-thirds of women at intervention clinics receiving a booklet. At other clinics there were also variations, reflecting the different levels of commitment and motivation among staff.

Table 6. Percent of women and men reporting exposure to antenatal care booklet

\begin{tabular}{|l|c|c|}
\hline & $\begin{array}{c}\text { Intervention women \% } \\
(\mathbf{n = 7 2 6 )}\end{array}$ & $\begin{array}{c}\text { Intervention men \% } \\
(\mathbf{n}=\mathbf{5 9 5})\end{array}$ \\
\hline Received booklet & $68(\mathrm{n}=493)$ & $49(\mathrm{n}=292)$ \\
\hline Respondent read booklet & 92 & 74 \\
\hline Partner read booklet & 45 & 88 \\
\hline Discussed booklet content with partner & 50 & 74 \\
\hline Found booklet useful & 61 & 74 \\
\hline
\end{tabular}

A higher proportion of the women who received the booklet reported reading it, compared with men who had received it. Men appeared to be much more aware of whether their partner had read the book than women were about their male partners. Interestingly, about half of the women reported discussing the contents of the booklet with their partner, while nearly three-fourths of the men mentioned such discussions. It is possible that women were contemplating the specific content of the booklet when responding to this question, while men were referencing any discussion pertaining to the pregnancy and other reproductive health topics. A slightly higher proportion of the men also reported finding the booklet useful, relative to the women, perhaps because they have fewer sources and opportunities to learn about the topics covered. Half of the women who received the booklet reporting having discussed it with their partner, indicating a need to reconsider how to make this component of the intervention more salient. 


\section{Exposure according to service statistics}

If an intervention is going to foster desired changes in knowledge, attitudes and behaviors, the services associated with the intervention must be provided to a reasonably high percentage of antenatal clients. Two things need to occur: the nurses trained to provide the new services must actually provide them, and clients must use them. This section explores actual exposure to the intervention using information from various sources including service statistics, client flow analysis, an activity sampling study, and the posttest cohort questionnaire.

\section{Number of couples that attended group couple counseling}

Figure 3 shows, using information from service statistics, the number of couples that attended group couple counseling per month. In total, 542 couple visits were made for counseling at the six intervention clinics. The number of couples that attended the group couple counseling sessions declined over time from an initial high of over 80 couples per month to under 40 per month by the third month of the intervention and to 20 couples or less during the latter months of the intervention period.

Figure 3. Number of couples counseled per month

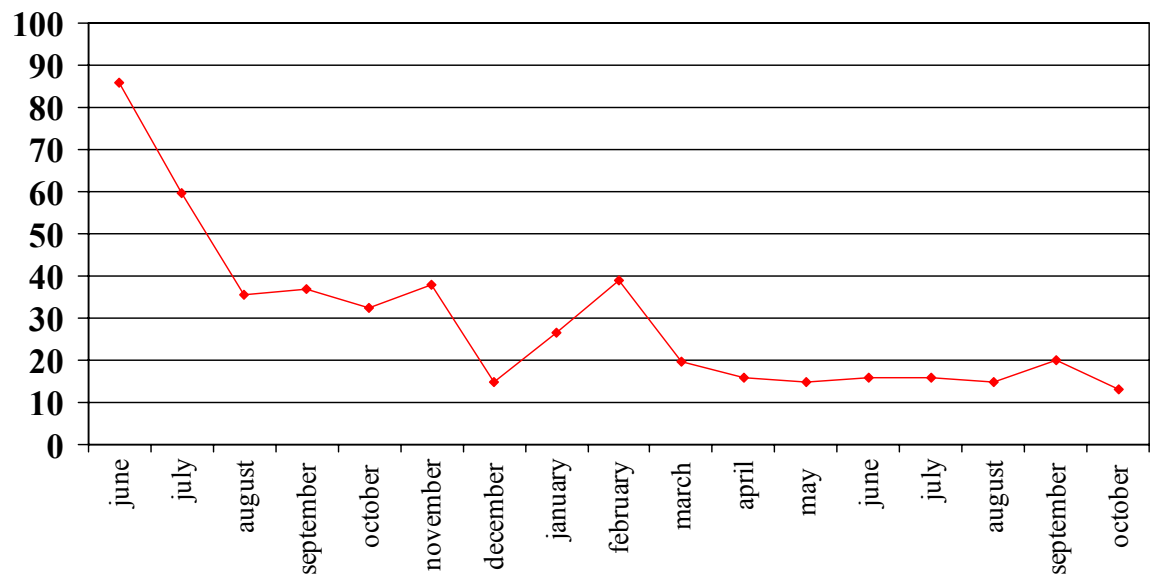

\section{Percent of couples that attended group couple counseling}

Service statistics and patient flow analysis calculation. The reach of the project can be determined by estimating the percentage of eligible couples that participated in the group couple counseling sessions. Because service statistics on the number of new antenatal clients that made visits to the clinics over the 18-month intervention period were not available, we estimated the number of new antenatal clients. We used information on visits made to the clinics during the two days covered by the client flow analysis. ${ }^{\text {iii }}$ We used the

\footnotetext{
iii We multiplied the number of visits per clinic by 70 which was the estimated number of weeks covered by the intervention period subtracting two weeks for Christmas and Easter holidays per year when visits are expected to be much lower.
} 
most conservative estimate for our denominator in order to come up with a minimum estimate for the percentage of women or couples that attended the sessions. Assuming that there were 87 clients per week (the number included in the posttest experimental group for the client flow analysis), over the 17-month period there would be 6510 new antenatal clients during the intervention period, and thus 6510 women or couples were eligible to attend the group couple counseling sessions. Given that 542 couples attended (in a few cases women attended alone), the estimated percent of those eligible to attend the sessions that did attend them was 8.3 percent. As seen in Table 5 above, about 45 percent of the women surveyed $(n=227)$, and 29 percent of the men $(n=136)$ reported attending couple counseling, either alone or with their partner. The service was offered to all antenatal attendees, regardless of enrolment in the study, so the higher number reported from the clinic registers is not unusual.

\section{Information provided during regular antenatal visits}

While the client needs to make a special effort to attend group couple counseling sessions, clients may receive pertinent information during regularly scheduled antenatal care visits, either during an individual contact with a provider or during a group counseling session. This section compares counseling received during visits, in particular the exam contact, using the results from the activity sampling study, and time spent with a provider during the exam consultation using results from the client flow analysis. Because of concern with the quality of the data on counseling received during visits, we also present data on the length of the exam contact, the contact in which the provider is most likely to talk with the client. If the length of that contact increased in the experimental group, we might hypothesize that the reason for the change was that providers paid more attention to counseling.

Counseling during the exam contact. The most important contact is the one in which the client receives a physical exam. After all, the main reason that a client seeks services is to have an exam to ensure that the pregnancy is proceeding well or to address any problems that have arisen. The exam also provides an opportunity for the provider to counsel the client about the topics that were highlighted in the training.

If providers in the experimental group had talked more with their clients about the various components of the intervention, we would have expected to find that the number of topics discussed increased more in the experimental than in the control group. However, our initial results suggested that there was a decrease in the number of topics covered between the baseline and follow-up periods, and we attributed the change to differences in the persons doing the observations and to the training of observers. For the posttest, observers received more targeted training concerning when to record that a specific topic had been discussed, and they may have been less ready to record casual mention of topics, particularly "danger signs" and "action plan" as having been discussed. Because of these concerns, in Table 7, we therefore compare results for the experimental and control groups for the posttest only. It is apparent that the percentage of exam consultations in which various topics was discussed was low, with the average less than one in both groups although it was lower in the experimental group. 
Table 7. Percent of consultations in which providers discussed various topics during exams for ANC clients in the posttest

\begin{tabular}{lcc}
\hline & \multicolumn{2}{c}{ First visits } \\
\cline { 2 - 3 } & $\begin{array}{c}\text { Experimental } \\
\text { Percent }\end{array}$ & $\begin{array}{c}\text { Control } \\
\text { Percent }\end{array}$ \\
Topic & 20 & \\
\hline Danger Signs & 19 & 21 \\
Action Plan & 5 & 11 \\
STI/HIV & 7 & 17 \\
Condoms & 4 & 21 \\
Family Planning & 9 & 12 \\
Partner's role in ANC & 2 & 7 \\
Syphilis Test & 0 & 4 \\
Syphilis Results & & 0.96 \\
\hline Average number of topics & 0.65 & \\
discussed & & 70 \\
Percent of contacts in which no & 77 & $(84)$ \\
topics were discussed & $(85)$ & \\
$\mathrm{N}$ & & \\
\hline
\end{tabular}

We measured the length of the exam contact using data from the Client Flow Analysis (CFA) and from the activity sampling. We tested for differences between the groups (prevs. posttest, experimental vs. control), as well as time trends and the two methodologies. ${ }^{\text {iv }}$ As expected, exam time is longer for new than for repeat clients. In addition, we found that the length of the exam decreased by about 2.5 minutes from the pre- to the posttest. Exam times were higher in the experimental group by 1 minute.

Table 8. Association of various factors that explain differences in the length of contacts (in seconds) for exams

\begin{tabular}{lcc}
\hline Factor & Regression coefficient & p-value \\
\hline CFA vs. Activity Sampling & 239 & .000 \\
First visit vs. Repeat & 292 & .000 \\
Pretest vs. Posttest & 146 & .000 \\
Control Group vs. Experimental & -59 & .055 \\
\hline
\end{tabular}

$\mathrm{R}^{2}=.095$

The very small difference in the length of exam time between the experimental and control groups, as well as the decrease in the length of the exam contact all indicate that counseling time was unlikely to have increased in the experimental group during the ANC visit.

\footnotetext{
${ }^{\text {iv }}$ We did find (Table 8 ) that the length of the exam was longer in the CFA by about 4 minutes than for activity sampling. In some cases, the time that the client spent waiting in the exam room may have been included in contact time in the CFA. Thus, contact time is over-estimated in the CFA.
} 
Counseling during the group talks. One reason for this low percentage of topics discussed in exam consultations is that nurses may have used the group talks rather than individual contacts as a venue to provide information. Table 9 provides information on the various topics discussed in the group talks in the experimental and control groups. It should also be noted that there were two clinics in the control group that did not have a group talk either on the days that the CFA or the activity sampling was carried out. The table refers to the small number of providers who conducted group talks that were observed during activity sampling. The major difference is that nurses in the experimental group were more likely to talk about some topics emphasized by the intervention (e.g., family planning, partner ANC) but not others (e.g. condoms, syphilis testing and results). It may be that these topics were more fully addressed in the group counseling sessions to which clients brought their partners, but no observations were made of these sessions.

\begin{tabular}{lcc}
$\begin{array}{l}\text { Table 9. Percent of group talks in which various topics } \\
\text { group }\end{array}$ & Expere discussed by \\
\hline Topic & 73 & Control \\
\hline Danger Signs & 82 & 83 \\
Action Plan & 82 & 83 \\
STI/HIV & 55 & 83 \\
Condoms & 36 & 83 \\
Family Planning & 73 & 17 \\
Partner's role in ANC & 18 & 50 \\
Syphilis Test & 9 & 33 \\
Syphilis Results & $(11)$ & 33 \\
N & & $(6)$ \\
\hline
\end{tabular}

\section{Conclusion}

A number of factors worked against full implementation of the intervention, including staff attrition, issues about performance bonuses, ambivalence about male participation, and weak supervision due to lack of transport and security concerns. In addition, some nurses found it a burden to record the names and numbers of those attending, so clinic registers likely underestimate the number of couples who actually presented for counseling. The data in this section suggest that the intervention would be expected to have only a minimal impact on knowledge, attitudes and behaviors. This is because (1) the percentage that attended group couple counseling is low, (2) counseling during the exam contact in the experimental group was similar to that in the control group, and (3) there were no consistent differences between group counseling sessions in the experimental and the control groups. 


\section{Family planning}

Hypothesis 1: Exposure to the intervention will have a positive impact on men and women's use of family planning at six months postpartum.

Use of modern method family planning by sexually active women

There was a significant difference between the control and intervention group on resuming sexual activity. Over two-thirds of women in the intervention $(72 \%)$ had resumed sexual activity at follow-up interview, compared with only 60 percent of women in the control group ( $\mathrm{p}=0.005)$. Resumption of sexual relations was included as a topic in the counseling and potentially may have caused couples to resume sexual activity earlier then the controls. Only women who had resumed sexual activity were included in the following analysis. The majority of sexually active women in both intervention and control $(89.6 \%$ and $89.2 \%$ respectively) were using a modern method of family planning when interviewed at six months postpartum (Table 10). The pattern of contraceptive use was very similar in the two groups. Less then 2 percent reported that they were using two methods of family planning (dual method use) six months postpartum.

Table 10. Current method use by sexually active women at six months postpartum

\begin{tabular}{|l|c|c|}
\hline & $\begin{array}{c}\text { Control women \% } \\
(\mathrm{n}=395)\end{array}$ & $\begin{array}{c}\text { Intervention women \% } \\
(\mathrm{n}=526)\end{array}$ \\
\hline Any method use & 89.1 & 89.3 \\
\hline Any modern method & 89.1 & 88.5 \\
\hline Method used ${ }^{*}$ & $\mathbf{( n = 3 5 4 )}$ & $\mathbf{( n = 4 6 9 )}$ \\
\hline Sterilization & 3 & 4 \\
\hline Pill & 4 & 4 \\
\hline IUD & $<1$ & 85 \\
\hline Injection & 86 & 8 \\
\hline Condom & 8 & $<1$ \\
\hline Traditional method & 0 & $<1$ \\
\hline Who made final decision of method used & & $<1$ \\
\hline Provider & 2.5 & 43.4 \\
\hline Male partner & 1.7 & 49.6 \\
\hline Women & 50.5 & $<1$ \\
\hline Both equally & 42.9 & 5.7 \\
\hline Parents & $<1$ & 1.4 \\
\hline Missing / no response & & 1.4 \\
\hline
\end{tabular}

${ }^{*}$ Adds up more than $100 \%$ due to dual method use.

As there are no significant differences between the intervention and control groups on use of contraception or methods used at six months postpartum, we are unable to reject the null hypothesis that exposure to the intervention will not have a positive impact on family planning use. 


\section{Sexually transmitted infections}

Hypothesis 2: Exposure to the intervention will have a positive effect on men and women's STI knowledge and preventive behaviors at six months postpartum.

\section{Knowledge of sexually transmitted infections including HIV}

All participants had heard of HIV/AIDS and virtually all knew about STIs at baseline and at follow-up (Table 11). However, about a fifth of women in both groups could not identify any symptoms of an STI in women or men, and this did not improve significantly in the second interview.

Table 11. Percent of women and men reporting knowledge of STI pre- and postintervention

\begin{tabular}{|c|c|c|c|c|c|c|c|}
\hline & \multicolumn{3}{|c|}{ Control \% } & \multicolumn{4}{|c|}{ Intervention \% } \\
\hline & $\begin{array}{c}\text { Pre } \\
\text { Women } \\
(n=1081)\end{array}$ & $\begin{array}{c}\text { Post } \\
\text { Women } \\
(n=689)\end{array}$ & $\begin{array}{c}\text { Post } \\
\text { Men } \\
(n=556)\end{array}$ & $\begin{array}{c}\text { Pre } \\
\text { Women } \\
(n=995)\end{array}$ & $\begin{array}{c}\text { Post } \\
\text { Women } \\
(n=721)\end{array}$ & $\begin{array}{c}\text { Pre } \\
\text { Men } \\
(n=555)\end{array}$ & $\begin{array}{c}\text { Post } \\
\text { Men } \\
(n=601)\end{array}$ \\
\hline Heard of STI & 94 & 97 & 97 & 90 & 98 & 97 & 100 \\
\hline \multicolumn{8}{|c|}{ Symptom of STI in women } \\
\hline Unusual discharge & 58 & 64 & 47 & 54 & 65 & 58 & 58 \\
\hline Genital ulcer & 34 & 45 & 42 & 30 & 45 & 53 & 42 \\
\hline Burning with urination & 34 & 35 & 29 & 24 & 26 & 41 & 26 \\
\hline Lower abdominal pain & 10 & 11 & 8 & 8 & 9 & 9 & 8 \\
\hline $\begin{array}{l}\text { Don't know any } \\
\text { symptoms }\end{array}$ & 17 & 17 & 26 & 19 & 17 & 10 & 24 \\
\hline \multicolumn{8}{|c|}{ Symptom of STI in males } \\
\hline Unusual discharge & 41 & 38 & 51 & 34 & 41 & 48 & 52 \\
\hline Genital ulcers & 39 & 52 & 58 & 34 & 51 & 35 & 56 \\
\hline Burning with urination & 33 & 29 & 43 & 23 & 20 & 27 & 43 \\
\hline Lower abdominal pain & 9 & 9 & 11 & 6 & 8 & 8 & 13 \\
\hline $\begin{array}{l}\text { Don't know any } \\
\text { symptoms }\end{array}$ & 25 & 22 & 10 & 30 & 24 & 30 & 12 \\
\hline Heard of HIV & 100 & 100 & 99 & 100 & 100 & 99 & 100 \\
\hline \multicolumn{8}{|c|}{ Ways to become infected with HIV } \\
\hline Sexual intercourse & 97 & 100 & 97 & 97 & 100 & 98 & 99 \\
\hline $\begin{array}{l}\text { Sharing of sharps } \\
\text { (needles and razor } \\
\text { blades). }\end{array}$ & 38 & 31 & 34 & 26 & 27 & 44 & 29 \\
\hline Blood transfusion & 22 & 17 & 16 & 14 & 9 & 25 & 6 \\
\hline Mother to child & 11 & 11 & 8 & 7 & 18 & 12 & 11 \\
\hline $\begin{array}{l}\text { Don't know any } \\
\text { symptoms }\end{array}$ & 1 & 0 & 0 & 2 & 0 & 0 & 0 \\
\hline \multicolumn{8}{|c|}{ Ways to prevent STI including HIVIAIDS } \\
\hline Use condom & 94 & 96 & 94 & 92 & 96 & 95 & 95 \\
\hline Be faithful & 38 & 36 & 39 & 33 & 43 & 42 & 44 \\
\hline Abstain & 22 & 5 & 5 & 22 & 4 & 4 & 7 \\
\hline $\begin{array}{l}\text { Encourage partner to } \\
\text { be faithful }\end{array}$ & 13 & 12 & 15 & 17 & 5 & 18 & 6 \\
\hline Avoid sharing sharps & 13 & 9 & 8 & 8 & 8 & 23 & 7 \\
\hline Do not know & 1 & 0 & $<1$ & 2 & $<1$ & 0 & 0 \\
\hline
\end{tabular}


Discharge was the most commonly cited symptom in women, noted by both women and men, and both discharge and genital ulcers were mentioned as symptoms seen in men. There was no statistically significant difference between the groups in knowledge of STIs. The prevailing finding is that little more than half of the respondents of either sex could name visible or physical symptoms of STIs.

When asked to name means of becoming infected with HIV/AIDS, nearly all respondents mentioned sexual intercourse, with no differences between groups or sexes. Alarmingly, given the level of mother to child transmission documented in South Africa, only around 10 percent of respondents mentioned this. For this sexually active population, few mentioned abstinence as a means to prevent STIs and HIV/AIDS, and only about 40 percent mentioned fidelity. Nearly all knew that using a condom was an effective way to prevent STIs.

\section{STI preventive behavior in male partners}

Around a fifth of men in both groups reported having sex with another partner in the six months since delivery of the baby (Table 12). There was no significant difference between the control and the intervention groups in risk behavior for STIs or in condom use with either regular or non-regular partners.

Table 12. Prevalence of risky behavior and condom use by male partners

\begin{tabular}{|c|c|c|}
\hline Behavior & $\begin{array}{c}\text { Control men } \\
\%\end{array}$ & $\begin{array}{c}\text { Intervention men } \\
\%\end{array}$ \\
\hline Sex with non-regular partner & $17(n=558)$ & $23(n=608)$ \\
\hline Condom used with non-regular partner & $61(n=95)$ & $61(n=140)$ \\
\hline $\begin{array}{l}\text { Whether used at last sex with non-regular } \\
\text { partner }\end{array}$ & $57(n=95)$ & $60(n=140)$ \\
\hline Who decided to use the condom & $(n=54)$ & $(n=84)$ \\
\hline \begin{tabular}{l|l} 
& Myself \\
\end{tabular} & 42 & 33 \\
\hline Partner & 1 & 3 \\
\hline Both & 19 & 24 \\
\hline Condom use with regular partner & $(n=558)$ & $(n=608)$ \\
\hline Condom use with regular partner & 46 & 58 \\
\hline Condom use at last sex with regular partner & $30(n=258)$ & $40(n=345)$ \\
\hline Who decided to use the condom & $(n=73)$ & $(n=136)$ \\
\hline \begin{tabular}{l|l} 
& Myself \\
\end{tabular} & 10 & 9 \\
\hline Partner & 18 & 10 \\
\hline \begin{tabular}{l|l}
\cline { 2 - 2 } & Both \\
\end{tabular} & 72 & 81 \\
\hline Dual method use with regular partner $^{+}$ & 34 & 43 \\
\hline
\end{tabular}

+ In this instance, dual method use refers to use of condom while using another modern method of family planning.

\section{Syphilis testing and management}

Syphilis testing and management is mandatory in South Africa; however, the formative research showed there were problems in the transport system that slowed turnaround time, and many women were not aware why their blood was being taken. Almost all women had a blood test in both control and intervention clinics (Table 13), but only two-thirds to threefourths knew what the test was for. About half recalled being given their test results, indicating either a lack of comprehension on the part of the women, or persistent problems 
in test management at the clinic level. The prevalence of syphilis was low with only 22 women in the control group and 18 in the intervention group reporting a positive result.

The lack of significant findings in STI and HIV/AIDS knowledge, risk behavior, and syphilis testing and management means that the null hypothesis cannot be rejected.

Table 13. Syphilis testing and management among women

\begin{tabular}{|l|c|c|}
\hline Variable & $\begin{array}{c}\text { Control women \% } \\
(\mathbf{n}=\mathbf{6 8 9})\end{array}$ & $\begin{array}{c}\text { Intervention women \% } \\
(\mathbf{n}=\mathbf{7 2 8})\end{array}$ \\
\hline Had blood test & 94 & 92 \\
\hline Knew what test was for & $67(\mathrm{n}=649)$ & $78(\mathrm{n}=670)$ \\
\hline Management & $(\mathbf{n}=\mathbf{4 3 5})$ & $\mathbf{( n = 5 2 5 )}$ \\
\hline Result given & 55 & 56 \\
\hline & Number & Number \\
\hline Told to get treatment & 22 & 18 \\
\hline Was treated & 21 & 15 \\
\hline Partner was treated & 21 & 15 \\
\hline
\end{tabular}

\section{Dual protection knowledge}

Hypothesis 3: Exposure to the intervention will increase clients' knowledge of dual protection provided by condoms (i.e., protection from STIs and unwanted pregnancy).

Knowledge of dual protection provided by condoms was significantly higher in the intervention group women compared to controls $(\mathrm{p}=0.02)$ (Table 14), while control group women were more likely to report condoms as a means to prevent transmission of STIs. Intervention group men were more likely than control men to mention condom's function only in preventing STIs.

Table 14. Percent of women and men reporting knowledge of uses of condoms

\begin{tabular}{|c|c|c|c|c|c|c|}
\hline \multirow{3}{*}{$\begin{array}{l}\text { Reasons to use } \\
\text { condoms }\end{array}$} & \multicolumn{4}{|c|}{ Women } & \multirow{2}{*}{\multicolumn{2}{|c|}{$\begin{array}{c}\text { Men } \\
\text { Post } \\
\end{array}$}} \\
\hline & \multicolumn{2}{|c|}{ Pre } & \multicolumn{2}{|r|}{ Post } & & \\
\hline & $\begin{array}{l}\text { Control } \\
(n=1064)\end{array}$ & $\begin{array}{c}\text { Intervention } \\
(n=989)\end{array}$ & $\begin{array}{l}\text { Control } \\
(n=694)\end{array}$ & $\begin{array}{c}\text { Intervention } \\
(n=729)\end{array}$ & $\begin{array}{l}\text { Control } \\
(n=557)\end{array}$ & $\begin{array}{l}\text { Intervention } \\
(n=607)\end{array}$ \\
\hline Dual protection & 65 & 64 & 69 & $76^{*}$ & 84 & 75 \\
\hline STI prevention only & 33 & 34 & $27^{*}$ & 21 & 14 & $21^{*}$ \\
\hline $\begin{array}{l}\text { Pregnancy } \\
\text { protection only }\end{array}$ & 2 & 2 & 2 & 3 & 2 & 3 \\
\hline $\begin{array}{l}\text { Do not know/ no } \\
\text { response }\end{array}$ & & & $<1$ & & & $<1$ \\
\hline
\end{tabular}

The intervention appears to have had a significant effect in improving the knowledge of condoms in providing dual protection among women exposed to counseling and the booklet. No improvement was seen in the male partners of these women. 


\section{Male involvement, support and communication}

Hypothesis 4: Exposure to the intervention will have positive effects on inter-spousal communication and support on reproductive health matters.

\section{Partner communication}

Both men and women were asked about the topics they discussed during the maternity period. For this analysis only matched couples were used (where both partners of a couple were interviewed). Table 15 shows topics discussed by couples, reported in the post delivery interview. Reported levels of discussion were higher in the intervention group. Significantly more intervention couples discussed topics related to STI, sexual relations, immunization and breastfeeding.

Table 15. Issues discussed by matched couples

\begin{tabular}{|l|c|c|}
\hline Topics Discussed & $\begin{array}{c}\text { Control couples \% } \\
\text { (n=528) }\end{array}$ & $\begin{array}{c}\text { Intervention couples \% } \\
\text { (n=588) }\end{array}$ \\
\hline STI & 64 & $75^{*}$ \\
\hline Sexual relation & 75 & $81^{*}$ \\
\hline Family planning & 70 & 77 \\
\hline Whether to have more children & 49 & 54 \\
\hline Immunization & 75 & $81^{*}$ \\
\hline Breastfeeding & 83 & $87^{*}$ \\
\hline Baby's health & 71 & 78 \\
\hline
\end{tabular}

${ }^{*} p<0.05$

About one-third of both control and intervention women reported that their partners assisted them in labor (including those who had a miscarriage) (Table 16). There were no significant differences in the level of assistance given by male partners between the two groups. Most men assisted by taking their partners to the hospital or by arranging for someone else to do so.

Table 16. Women's report of partners' involvement during labor

\begin{tabular}{|l|c|c|}
\hline & $\begin{array}{c}\text { Control women \% } \\
(\mathbf{n = 6 9 2 )}\end{array}$ & $\begin{array}{c}\text { Intervention women \% } \\
(\mathbf{n = 7 2 6})\end{array}$ \\
\hline Partner assisted & 33 & 38 \\
\hline Action taken * & $(\mathbf{n = 2 2 9 )}$ & 61 \\
\hline Took her to hospital to280) \\
\hline $\begin{array}{l}\text { Arranged someone to take her to } \\
\text { hospital }\end{array}$ & 61 & 31 \\
\hline Arranged transport & 31 & 19 \\
\hline Comforted her & 13 & 8 \\
\hline
\end{tabular}

*Multiple responses

There is limited support for this hypothesis, with couples exposed to the intervention significantly more likely to report discussing STIs, sexual relations, immunization and breastfeeding, compared with the control couples. No differences were observed in support provided around the time of delivery. 


\section{Knowledge of danger signs, problems experienced during pregnancy and action taken}

A secondary hypothesis was added to the study, stating that: More women in the intervention group than in the control group will have correct knowledge of obstetric danger signs, and seek care in a timely fashion if faced with one of these. The researchers realized this was being measured, but that the proposal did not include an explicit hypothesis to be tested. Neither the intervention nor data collection were altered to address the hypothesis.

\section{Knowledge about danger signs in pregnancy}

There were no significant differences in knowledge of danger signs between intervention and control women at baseline, nor were there any differences at end line for either women or men. Among all partners, male and female, bleeding and high blood pressure were the most commonly known danger signs, yet these were mentioned by no more than 60 percent of the respondents (and as few as 22 percent).

About one-third of the women, both intervention and control, reported knowing one or two danger signs, with no significant differences shown.

Table 17. Knowledge of danger signs during pregnancy

\begin{tabular}{|l|c|c|c|c|c|c|c|}
\hline & \multicolumn{3}{|c|}{ Pre } & \multicolumn{3}{c|}{ Post } \\
\cline { 2 - 8 } & $\begin{array}{c}\text { Control } \\
\text { women } \\
(\mathbf{n = 1 0 6 7 )}\end{array}$ & $\begin{array}{c}\text { Intervention } \\
\text { women } \\
(\mathbf{n = 9 9 4 )}\end{array}$ & $\begin{array}{c}\text { Intervention } \\
\text { men } \\
(\mathbf{n = 5 8 4})\end{array}$ & $\begin{array}{c}\text { Control } \\
\text { women } \\
(\mathbf{n = 6 9 4 )}\end{array}$ & $\begin{array}{c}\text { Intervention } \\
\text { women } \\
(\mathbf{n = 7 2 9})\end{array}$ & $\begin{array}{c}\text { Control } \\
\text { men } \\
(\mathbf{n = 5 5 5})\end{array}$ & $\begin{array}{c}\text { Intervention } \\
\text { men } \\
(\mathbf{n = 6 0 1})\end{array}$ \\
\hline $\begin{array}{l}\text { Danger } \\
\text { signs } \\
\text { known+ }\end{array}$ & & & & & & & \\
\hline Fever & 30 & 27 & 30 & 20 & 34 & 15 & 31 \\
\hline Bleeding & 58 & 43 & 24 & 50 & 51 & 25 & 22 \\
\hline Swelling & 7 & 5 & 8 & 15 & 10 & 10 & 11 \\
\hline $\begin{array}{l}\text { High } \\
\text { blood } \\
\text { pressure }\end{array}$ & 34 & 26 & 43 & 55 & 57 & 41 & 45 \\
\hline $\begin{array}{l}\text { Pre-labor } \\
\text { rupture of } \\
\text { membrane }\end{array}$ & 25 & 12 & 9 & 13 & 16 & 3 & 3 \\
\hline $\begin{array}{l}\text { Knows no } \\
\text { danger } \\
\text { signs }\end{array}$ & 7 & 11 & 9 & 5 & 3 & 30 & 18 \\
\hline
\end{tabular}

+ Multiple responses permitted.

\section{Experiencing danger signs and action taken}

More than a third of women in both groups experienced one or more warning signs (Table 18). Most women went to the hospital as advised; however, 10 percent of intervention women and six percent of control women did nothing when the problem arose (Table 15). 
In an emergency situation a significantly higher proportion of the intervention men assisted their partners compared to control men $(p=0.004)$

Table 18. Percent of women experiencing danger signs during index pregnancy and actions taken

\begin{tabular}{|c|c|c|}
\hline & $\begin{array}{c}\text { Control Women } \\
(n=694)\end{array}$ & $\begin{array}{c}\text { Intervention Women } \\
(\mathrm{n}=729)\end{array}$ \\
\hline \multicolumn{3}{|l|}{ Had problems during pregnancy } \\
\hline Yes & 39 & 38 \\
\hline Problems experienced & $(n=270)$ & $(n=274)$ \\
\hline Fever & 38 & 40 \\
\hline Bleeding & 31 & 28 \\
\hline High blood pressure & 45 & 42 \\
\hline Pre-labor rupture of membrane & 38 & 23 \\
\hline Swelling of face and hands & 28 & 31 \\
\hline Foul smelling discharge & 12 & 6 \\
\hline \multicolumn{3}{|c|}{ Women reporting partner assistance during emergencies } \\
\hline Action taken+ & $(n=270)$ & $(n=274)$ \\
\hline Nothing & 6 & 10 \\
\hline Went to the clinic & 22 & 23 \\
\hline Went to hospital & 64 & 63 \\
\hline Went to the doctor & 2 & 1 \\
\hline Called the ambulance & $<1$ & $<1$ \\
\hline Called for help & $<1$ & $<1$ \\
\hline \multicolumn{3}{|l|}{ Partner assisted } \\
\hline Partner assisted & $30(n=83)$ & $43^{*}(n=119)$ \\
\hline \multicolumn{3}{|l|}{ What did partner do+ } \\
\hline Took me to clinic & 5 & 7 \\
\hline Took me to the hospital & 64 & 46 \\
\hline Took me to the doctor & 1 & 7 \\
\hline Arranged someone to take me & 12 & 16 \\
\hline Arranged transport & 22 & 17 \\
\hline Gave me money & 0 & 16 \\
\hline Other & 0 & $<1$ \\
\hline
\end{tabular}

${ }^{*} p<0.05$

+ Multiple responses permitted.

The intervention may have had some limited impact in improving the intervention group men's willingness to assist their partners during a pregnancy-related emergency, but in general the evidence is not compelling; the null hypothesis is not rejected. 


\section{Breastfeeding}

Hypothesis 5: Exposure to the intervention will have positive effects on selected indicators of infant health, particularly exclusive baby feeding practices.

\section{Pregnancy outcome}

A total of 640 control and 679 intervention women gave birth to live babies (Table 19). Some of these babies died during their first week of life, and further deaths occurred between seven days and six months post delivery. At follow-up a similar proportion of women had lost their babies in both the intervention (11\%) and control (12\%) sites. Investigating causes of death was beyond the scope of the study; however, the frequency of infant deaths is notably high.

Table 19. Percent distribution of pregnancy outcomes

\begin{tabular}{|l|c|c|}
\hline Pregnancy outcome & $\begin{array}{c}\text { Control Women \% } \\
(\mathbf{n = 6 9 4 )}\end{array}$ & $\begin{array}{c}\text { Intervention Women \% } \\
(\mathbf{n = 7 2 9})\end{array}$ \\
\hline Baby alive at follow-up & 88 & 89 \\
\hline Abortion or miscarriage & 3 & 4 \\
\hline Stillbirth & 4 & 2 \\
\hline Born alive died within 7 days & 2 & 1 \\
\hline Born alive died between 7 days and 6 months & 3 & 3 \\
\hline
\end{tabular}

\section{Breastfeeding patterns}

Baby feeding questions were asked of mothers whose babies survived beyond seven days. Both breast and formula feeding practices, reasons for not breastfeeding, whether partner assisted during baby feeding, and time of introducing other food as a proxy for exclusive feeding were all assessed.

Around three-quarters of women (73\% control and 74\% intervention) were breastfeeding at follow-up (Table 20). There were no significant differences in breastfeeding practices between the intervention and control groups.

The women were not asked about whether or not they had been tested for HIV during their pregnancy or their HIV serostatus, which may have affected their decisions about breastfeeding. Nevertheless, in the context of South Africa, it is disturbing that few women breastfed exclusively until six months.

The intervention appears to have made no difference in immunization or baby feeding practices, as no significant differences were detected between these two groups. 
Table 20. Breastfeeding practices

\begin{tabular}{|c|c|c|}
\hline & $\begin{array}{c}\text { Control women \% } \\
(n=627)\end{array}$ & $\begin{array}{c}\text { Intervention women \% } \\
(n=671)\end{array}$ \\
\hline Currently breastfeeding & 73 & 74 \\
\hline Currently not breastfeeding & $(n=153)$ & $(n=164)$ \\
\hline Has breastfed the baby & 74 & 77 \\
\hline Has never breastfed & 26 & 23 \\
\hline First time baby put on the breast & $(n=592)$ & $(n=630)$ \\
\hline Immediately & 63 & 66 \\
\hline Within 1 hour & 16 & 17 \\
\hline Within a day & 12 & 10 \\
\hline Later than a day & 6 & 7 \\
\hline Mixed feeding at six months & 94 & 95 \\
\hline Commenced mixed feeding (months) & $(n=581)$ & $(n=629)$ \\
\hline $0-2$ & 34 & 30 \\
\hline $3-5$ & 58 & 59 \\
\hline 6 & 8 & 11 \\
\hline \multicolumn{3}{|l|}{ Partner assisted in breastfeeding } \\
\hline Partner helped & 72 & 77 \\
\hline \multicolumn{3}{|l|}{ Reason for stopping breastfeeding } \\
\hline Not well / advised by provider to stop & 10 & 13 \\
\hline Breastfeeding problem & 56 & 49 \\
\hline Baby related (including infant deaths) & 5 & 13 \\
\hline Advised by someone else (mother or partner) & 5 & 13 \\
\hline Other & 18 & 24 \\
\hline
\end{tabular}

\title{
Client and provider satisfaction with the intervention
}

\author{
Hypothesis 6: Exposure to the intervention will have positive effects on clients' and \\ providers' satisfaction with antenatal and postnatal care services.
}

\section{Clients' satisfaction}

The level of satisfaction with services was high in both groups, with no significant differences between them. Ninety percent of the women in the control group and 95 percent in the intervention group reported that they would return to the clinic for RH services, as did 84 percent of control and 91 percent of intervention men. The addition of the MiM services did not appear to distinguish the intervention clinics, and the client responses are consistent with other findings in South Africa, where clients typically are not critical of long waiting times or curt service.

\section{Providers' views of the intervention}

Three focus group discussions (FGD) were held with providers at the six intervention clinics to assess provider satisfaction with the intervention. A separate FGD was held for each category of staff (person in charge, registered midwives and assistant nurses) to ensure homogeneity of the group. Each group had six participants $(\mathrm{N}=18)$. Most of the nurses had worked in antenatal care for more than five years. All were trained in the intervention at the beginning of the project and some were part of the technical task teams during the planning 
phase. Providers were asked to discuss their perceptions and feelings about the intervention during different stages of the project:

- project introduction

- project implementation

- project completion after almost two years.

Providers were also asked about what motivated them to continue with the intervention activities. Previous experiences and social environment were the major influence on providers' perceptions of the project at the introductory stage. Some of the providers had worked in the clinics for more than ten years and they viewed antenatal care as a woman's domain. Some nurses had experienced couple counseling in hospitals where women had attended antenatal care with their partners (however this had been included in ANC services directed to other racial groups). Other nurses had not been exposed to any services where partners were involved, in particular in rural areas where, traditionally, men were not involved in pregnancy and birth-related activities.

There were those who did not like the idea of having men involved in maternity, some were concerned that the social environment and culture would have negative influences on men when they were invited to come for couple counseling.

"I thought men would not come since we work in the rural area."

"I was concerned about culture."

One of the nurses showed negative feeling towards the project team.

"I was frustrated of what was going to be expected of us... and I thought that this was going to be a way of continuous inspection."

Some viewed this as an opportunity that was needed.

"Males do not normally use clinic services so I thought this was going to give us an opportunity to counsel men."

Discussion on project implementation showed that they all felt positively about the project and they felt they also benefited from it. Most felt that the project improved their working environment and the way they did their work. As a result they felt that antenatal care had been improved. Some felt that it provided the long overdue opportunity to talk directly to men on specific male-related reproductive issues

"It has helped us educate men on how to use condoms."

They also indicated that this was not easy to start, but the training they received motivated them to become more involved. Some indicated that it was difficult to continue with the project because of shortages of staff but they felt that they remained encouraged because they were seeing positive changes.

"Positive response from men when they were invited for couple counseling made us continue."

"Seeing positive changes on couples, some even got married and invited us."

In general, discussions and opinions expressed by providers on the acceptability and feasibility of male participation were more positive following the intervention. 


\section{Cost analysis}

Hypothesis 7: The experimental intervention will produce the hypothesized results in a cost-effective manner, both in terms of its marginal and total cost as well as any additional opportunity cost that is incurred for the new services.

\section{Activities in the various phases of the intervention}

Table 21 shows activities that occurred during the preparation, intervention and service delivery phases of the project and the resources used to carry out these activities. ${ }^{\text {vii }}$ Phase one included formative research that provided information to develop the intervention as well as the actual intervention. In the second phase, the main activity was training both trainers and health providers. In the third phase, services were provided to clients and service delivery was monitored and supervised.

Table 21. Activities and resources used during the intervention

\begin{tabular}{|c|c|}
\hline Phase / activities & Resources used \\
\hline \multicolumn{2}{|l|}{ Preparation } \\
\hline $\begin{array}{l}\text { Formative } \\
\text { research }\end{array}$ & Focus group discussions, RHRU time, attendee time \\
\hline $\begin{array}{l}\text { Design } \\
\text { intervention }\end{array}$ & $\begin{array}{l}7 \text { meetings: average of } 12 \text { participants per meeting, average of } 4 \\
\text { hour length, RHRU time, attendee time }\end{array}$ \\
\hline $\begin{array}{l}\text { Develop } \\
\text { curriculum }\end{array}$ & 1 meeting: 8 participants, 4 hours, RHRU time, attendee time \\
\hline Develop IEC & $\begin{array}{l}1 \text { meeting: } 19 \text { participants, } 8 \text { hours, consultant fee, RHRU time, } \\
\text { attendee time }\end{array}$ \\
\hline $\begin{array}{l}\text { Develop } \\
\text { supervisory tool }\end{array}$ & (2) \\
\hline $\begin{array}{l}\text { Preparatory } \\
\text { meeting for TOT }\end{array}$ & 1 meeting: 4 participants, 4 hours, RHRU time, attendee time \\
\hline $\begin{array}{l}\text { Miscellaneous } \\
\text { meetings }\end{array}$ & RHRU time dedicated to preparation phase \\
\hline \multicolumn{2}{|l|}{ Implementation } \\
\hline Training of trainers & 1 session: 6 participants for 3 days \\
\hline $\begin{array}{l}\text { Health provider } \\
\text { training }\end{array}$ & 3 sessions: 5 days each, average of 21 participants per session \\
\hline IEC materials & Printing \\
\hline Clinic restructuring & Upgrading clinic equipment \\
\hline \multicolumn{2}{|l|}{ Service delivery } \\
\hline $\begin{array}{l}\text { Group couple } \\
\text { counseling }\end{array}$ & $\begin{array}{l}149 \text { sessions at } 6 \text { clinics over } 18 \text { months, average of } 1.4 \text { sessions } \\
\text { per month per clinic, average of } 3.6 \text { couples per session per clinic, } 1 \\
\text { hour per session }\end{array}$ \\
\hline $\begin{array}{l}\text { Supervision and } \\
\text { monitoring }\end{array}$ & $\begin{array}{l}1821 \text { hours spent over } 18 \text { months, average of } 101 \text { hours per month, } \\
\text { average of } 25 \text { hours per person per month ( } 4 \text { RHRU staff) }\end{array}$ \\
\hline
\end{tabular}

\footnotetext{
vii There was no change in the length of interactions with providers during regular ANC visits so that the cost of these visits is not included in service delivery costs.
} 
During phase three, 542 couple contacts were made during the group counseling sessions (149 sessions X 3.6 couples per session). ${ }^{\text {viii }}$ The reach of the project, as discussed in the section on exposure to the intervention, was determined by estimating the percentage of eligible couples that participated in the group couple counseling sessions. We estimated that 6510 women or couples were eligible to attend counseling, and clinic registers show 542 couples attended (which likely underestimated the actual attendance as it is known that at least two registers were unused for part of the intervention period), the estimated percent eligible to attend who did attend was 8.3 percent.

\section{Total costs, costs per clinic, and costs per client}

Table 22 shows the costs of the intervention were almost 1 million rand with the highest costs incurred in the preparation phase. These included the costs of conducting the formative research and the cost of time spent either in meetings or working alone to develop the intervention. The implementation phase mostly includes the costs of training while the service delivery phase includes the costs of supervision and monitoring and of the delivery of services in the group couple counseling sessions. The costs of monitoring and supervision are much higher than those for service delivery.

Table 22. Financial and non-financial costs of three phases of intervention (ZAR)

\begin{tabular}{|c|c|c|c|c|}
\hline & Financial & $\begin{array}{l}\text { Financial and Non- } \\
\text { financial Labor }\end{array}$ & $\begin{array}{c}\text { Non-financial } \\
\text { Labor }\end{array}$ & \\
\hline Phase / activities & $\begin{array}{c}\text { Meals, transport, } \\
\text { materials }\end{array}$ & $\begin{array}{c}\text { (RHRU and } \\
\text { consultant fees) }\end{array}$ & DOH & Total \\
\hline \multicolumn{5}{|l|}{ Preparation } \\
\hline Formative research & 9,020 & 148,966 & & 157,986 \\
\hline Developing intervention & 11,251 & 348,688 & 29,439 & 389,378 \\
\hline Sub-total & 20,271 & 497,654 & 29,439 & 547,364 \\
\hline \multicolumn{5}{|l|}{ Intervention } \\
\hline Training of trainers & 815 & 4,755 & 15,718 & 21,288 \\
\hline Health provider training & 22,739 & 22,217 & 92,125 & 137,081 \\
\hline IEC materials & 56,704 & - & & 56,704 \\
\hline Clinic restructuring & 43,259 & - & & 43,259 \\
\hline Sub-total & 123,517 & 26,972 & 107,843 & 258,332 \\
\hline \multicolumn{5}{|l|}{ Service delivery } \\
\hline Group couple counseling & - & - & 5,167 & 5,167 \\
\hline Supervision/monitoring & - & 164,657 & - & 164,657 \\
\hline Sub-total & - & 164,657 & 5,167 & 169,824 \\
\hline Total (in ZAR) & 143,788 & 689,283 & 142,449 & 975,520 \\
\hline
\end{tabular}

US \$1 = 10 ZAR

\footnotetext{
viii Service statistics provided by the RHRU were used to estimate the number of couples that attended the group counseling sessions over the 18-month period of the intervention.
} 
The preparation phase costs are dominated by RHRU's cost to develop the intervention. Intervention phase costs are almost evenly split between financial costs and non-financial DOH labor costs. The service delivery phase costs are dominated by RHRU time spent supervising and monitoring the intervention.

The costs for meals, materials and transportation are financial and required payment for services. The costs of involving the staff of the $\mathrm{DOH}$ in attending training sessions or in delivering services are non-financial as these persons are employed by the DOH and took time away from their regular activities in order to carry out project-related activities. However, the costs for the RHRU staff include both financial and non-financial costs. Staff members were paid to work on various aspects of the intervention but they reported that they spent additional unpaid hours on the project, and the costs reported in Table 20 include the value of all time spent on the project, regardless of whether the staff members were paid for that time.

Table 23 shows that the costs per clinic were over 162,000 rand, the costs per staff member trained were 15,000 rand and that the costs per couple reached were about 1800 rand. If the intervention were to be expanded to other clinics, then the costs incurred in the first phase would probably be lower since the intervention has already been designed. However, given the limited reach and success of the intervention, additional time and costs would likely be required in order to redefine the intervention statusbased on lessons learned. The ongoing implementation costs at the six clinics would also be somewhat lower as clinic restructuring would not have to occur every year. Training costs, at least for health personnel, would remain high. ${ }^{\text {ix }}$ Finally, the costs in the service delivery phase are dominated by supervision and monitoring and these could be reduced through decreases in the number of supervisory visits.

Table 23. Total cost, cost per clinic and cost per couple counseled by project phase

\begin{tabular}{|l|r|r|c|c|}
\hline Phase & Total costs & Cost per clinic & $\begin{array}{c}\text { Cost per person } \\
\text { trained }\end{array}$ & $\begin{array}{c}\text { Cost per couple } \\
\text { counseled }\end{array}$ \\
\hline Preparation phase & 547,364 & 91,227 & 8421 & 1,011 \\
\hline Intervention phase & 258,332 & 43,055 & $3974^{*}$ & 477 \\
\hline Service delivery phase & 169,824 & 28,304 & 2613 & 314 \\
\hline Total (in ZAR) & $\mathbf{9 7 5 , 5 2 0}$ & $\mathbf{1 6 2 , 5 8 7}$ & $\mathbf{1 5 , 0 0 8}$ & $\mathbf{1 , 8 0 2}$ \\
\hline
\end{tabular}

${ }^{*}$ Note 3974 ZAR is cost per person trained using only TOT and health provider training costs.

In future years, the cost per clinic and per couple counseled would be much lower as the activities in the preparation phase do not have to be repeated. Thus, a better estimate of the ongoing costs of the intervention can be obtained by adding the costs for the intervention and the service delivery phases. Thus costs per clinic, person trained or per couple reached are less than half of the total in future years. Moreover, intervention costs on an annual basis are likely lower as clinic restructuring does not occur every year. In addition, if clinic

\footnotetext{
${ }^{\text {ix }}$ According to staff at the RHRU, turnover of staff at the clinics is very high suggesting that training costs be treated as recurrent costs.
} 
personnel were to continue at their jobs for a longer time period, then the annual costs per coupled counseled would be even lower. If the intervention was used by more people, the cost per couple counseled would also be lower. Nevertheless, even considering just the service delivery costs, the cost per couple counseled is over 300 Rand. Thus, other changes would be necessary to make the intervention affordable.

It should also be noted that if the intervention were to be expanded to other clinics, that some costs that are now financial costs would become non-financial costs. This is because the Department of Health would carry out the intervention using its own employees. While they would have to take time away from their regular work to carry out project activities, they are unlikely to receive additional compensation. Moreover, the salary scale at the $\mathrm{DOH}$ is lower than that at the RHRU, and switching activities from RHRU to DOH personnel would lower total costs. Thus, if the intervention were to be expanded to other clinics, through reductions in supervisory visits and in the costs of these visits, the cost per couple counseled in the service delivery phase could be reduced substantially below the 314 Rand shown in Table 23.

\section{DISCUSSION}

Although all women recruited gave consent to interview their partners and gave their contact details, study staff were unable to locate some men and women for follow-up. This was mainly due to the fact that women often gave incorrect addresses for their partners as well as themselves. Women living outside the catchment area of PMMH are known to give false addresses in order to attend one of the clinics that fall under this hospital. A large number of women changed addresses and most women were not living with their partners and it was often difficult to trace male partners residing at other addresses. In some instances male partners denied paternity.

There was a small difference in mean age of one year between women in the control and intervention groups that was statistically significant and was adjusted for in the analysis. There was very little difference in the background characteristics such as education, employment and relationship status within the groups. Data was similar to that of national figures. About half of the women in both groups were in the first three years of their relationship. Two-thirds were not living together with their partners. This was higher than 48 percent reported by the SADHS in 1998. The main reason for not living together even though the woman was pregnant was that couples were not married or that the relationship was "visiting". There could be several reasons for this including the need to pay "lobola x" to the family of the woman. Lobola is a price given to the bride's family, in the form of eleven or more cattle or money equivalent to this, depending on the status of the bride's father in the community. The daughters of chiefs and kings may require higher bride prices. This payment can be problematic for a man who is unemployed or unable to afford the asking price set by the family. 
Almost half of the participants in both groups were pregnant for the first time. Mean gestational age for the first visit for antenatal care was five months. Late presentation in pregnancy is one of the challenges facing maternal health care services in South Africa. The latest Saving Mothers Report (Pattinson, 2002) quoted a similar figure. The mean gestational age was slightly lower in the intervention group, resulting from a change in recruitment inclusion criteria. This was implemented due to a concern that women would not be fully exposed to the intervention before their delivery date.

The intervention demonstrated its feasibility in that at least a third of couples took the opportunity to attend the counseling. This was a very new concept in the community where male participation has previously been minimal, couples were not living together and some of the nurses were concerned that their culture did not promote male involvement. Some men were unable to attend counseling due to the nature of their work or they were unable to obtain permission from employers. In addition, limited health service working hours also excluded men. Some men had not been told by their partners of the counseling and so did not attend. All women, regardless of their attendance at the couple counseling, were exposed to the strengthened clinical service package in the intervention sites including health education.

The clinic sites were randomly assigned to either intervention or control and therefore as expected not all clinics had the same motivation to implement the project. Some clinics continued the couple counseling even when the study was completed while others required a great deal of extra support to keep the counseling going throughout the intervention period. Among the control sites, many were disappointed to have not been considered for the intervention and tried to improve their services knowing that other clinics were being trained and had introduced the counseling services. Within the intervention clinics there was a considerable range of commitment to the study. This was evident in the distribution of the "Ukuba Umzali" booklet, with some intervention clinics doing this consistently while others did not. As a result about two-thirds of the eligible women received " $U k u b a$ Umzali" during their antenatal care. Of these, two-thirds shared the booklet with their partners. The response to the booklet was very positive from all those who read it. Almost all men who read the booklet found it useful compared to two-thirds of the women.

Male involvement and communication reflected positive responses to men becoming involved in almost all aspects of the ANC process with some hesitation around labor and delivery. In part this may reflect concerns about waiting facilities and privacy in labor and delivery wards. Responses were similar across both control and intervention groups.

Communication was generally high within the groups but on most topics a significantly higher proportion of intervention couples discussed key issues. These included topics related to STI, sexual relations, baby immunization, and breastfeeding.

Women's abstinence pre- and post-delivery was common in both groups. Almost a third of women post delivery were not yet sexually active at the time of the six month postpartum follow-up. There was no difference in the high levels of family planning use seen in both groups (almost 90\%), with most women relying on injectable contraceptives. The high level of prevalence was unexpected and is much higher then reported from the SADHS in 1998. Women may be motivated to use to avoid another pregnancy soon, especially since 
more than two-thirds reported at baseline that the pregnancy was unplanned. Also, nurses at PMMH may be proactive in insisting that women be discharged having already accepted a method.

Among those who were not sexually active over half were also using a method of family planning, typically injectables. A small percentage of women stated that the provider was the person who made the decision on the method they were using. It may be that most women felt they should accept a method if it was offered, raising the question of whether women were given a fully informed choice of method postpartum.

All participants had heard about STIs and HIV. Unusual discharge and genital ulcers were the most commonly known symptoms of STI. Men and women in both groups knew about unsafe sex as a mode of HIV transmission. Almost all men and women in both groups mentioned condom use and safe sex as methods of preventing STI and HIV.

Dual protection knowledge was relatively high among all the groups with two-thirds to three-fourths of women and men knowing about it. The increase in knowledge was significantly higher in the intervention women compared with control women.

There were no significant differences in the sexual behavior of men in the study. Around 20 percent of both intervention and control men reported having sex with non-regular partners within the last six months. It is not uncommon for male partners to have a sexual network with non-regular partners during the post-natal period. Lawoyin and Larsen (2002) reported that 48 percent of male partners in Nigeria admitted having a sexual network while their partners were abstaining post delivery and that condom use with these non-regular partners was low and condom use with regular partner was absent. ${ }^{16}$ Men have power to protect themselves, women and babies, yet the risk-taking and aggressive sexual behavior by men are often condoned by societies. ${ }^{17}$ This is common in KZN, and clearly drives the high HIV infection rate in the province as reported in the national HIV and syphilis sero-prevalence survey of women attending public antenatal clinics in South Africa. Two-thirds of intervention and control men who had non-regular partners did use condoms with these partners, but almost all said they used a condom on their last sexual encounter.

Orege of the Kenyan National AIDS Control Council pointed out that up to 80 percent of infections among women occurred in "stable relationships" where the man had become infected elsewhere. ${ }^{18}$ Only 30 percent of control men and 40 percent of intervention men reported using condoms with their regular partners, and there were no significant differences observed. While some couples may not need to use condoms, if they do not seek partners outside their monogamous relationship, condom use remains an effective protective strategy in a high prevalence country like South Africa.

There was no significant difference between the groups in syphilis testing rates. The intervention improved the transport system and turnaround time for the intervention clinics, however this would have also had a similar effect on the control sites as they are managed through the same district system. There was no difference between the groups in the proportion of women who knew what the test was for. The results are normally entered onto the ANC card carried by the client, but the provider may not have drawn the clients' 
attention to this. Of the women interviewed, less than 3 percent in the control and 2 percent in intervention group reported that they were told they needed treatment for syphilis.

There were no significant differences in knowledge of obstetric danger signs between control and intervention women. Of the women who experienced problems (around 40 percent in both groups), the intervention women were significantly more likely to be assisted by their partners. This is an important finding as early recognition of danger signs could help reduce maternal mortality.

Breastfeeding practice was seen as a key issue to address in the intervention, but no significant differences emerged between the groups as a result of exposure to the intervention. Normal practice in the community where the MIM study was conducted is breastfeeding with a considerable level of mixed feeding beginning as early as two months. Prior to the implementation of the intervention there was considerable debate on the promotion of exclusive breastfeeding and its protective effect in the transmission of HIV from mother to child. A comparative study had recently been published showing 15 percent of babies who were exclusively breastfed were infected with HIV. Although this was lower than the group who were given mixed feeding it raised concern. ${ }^{19}$ It was clear that there was very delicate balance between avoiding HIV transmission through breastfeeding and avoiding harm by promoting formula feeding. ${ }^{20}$ The Department of Health Division of $\mathrm{MCH}$ had adopted a baby friendly hospital approach which promoted exclusive breastfeeding, in recognition that many HIV positive women could not afford formula. Exclusive feeding is a new concept in the community, where previously babies were weaned with the introduction of solid foods as early as two to three months. This issue caused some confusion among the health workers and affected staff training and the content of messages given to clients during the study implementation. Ultimately it was agreed that women would be given all available information and the option to choose the strategy they thought best for their personal circumstances.

Many women were still breastfeeding at six months; however most were mixing feeding and there was no significant difference between the groups. More then three quarters had started mixed feeding when the baby was three months old. Although exclusive breastfeeding is being promoted, due to the lack of integration of services several messages were being communicated to the mother. Exclusive feeding is being associated with HIV. Studies have shown that even though formula feeding was provided free, only about half of women who chose to formula feed did this exclusively. Younger mothers, newly married in particular, were more likely to mix feed because of pressure from parent-in-laws who have considerable influence on the choice of infant feeding. ${ }^{21,}{ }^{22}$ Women try to avoid the stigma associated with exclusive formula feeding by taking different actions. Some women who

run out of formula give other supplements between feedings or dilute the formula. ${ }^{23}$ Baby feeding practices remain a challenge, but there were some women who exclusively breastfed their babies and a quarter of both groups of women gave formula feeding only in the early months of their babies' lives.

\section{UTILIZATION}

In the context of health care in South Africa, STIs and HIV/AIDS as well as maternal mortality, partnered deliveries, and involving men in reproductive health including PMTCT 
are current issues and priorities. These issues need to be addressed on a broad level given the need to strengthen even the basic antenatal care package introduced in the MIM study. There is an added burden in providing integrated new services in a fragmented and vertical health care system.

The project staff has had on-going feedback with provincial national DOH decision makers. Involvement of the $\mathrm{DOH}$ in planning, design and implementation of training was invaluable and has ensured continued interest in the issue of involving men and companioned antenatal and delivery services particularly at the provincial level. In addition to local presentations, international presentations were made on various aspects of the research and experiences of involving men in antenatal care (see Appendix 5). This has led to sensitization of all reproductive health programs, including the National Maternal Child and Women's Health (MCWH) programs, to the concepts of male involvement and making $\mathrm{RH}$ services male friendly. IEC materials for the provincial MCWH program have been based on the lessons learned from the project, specifically about male involvement. As a result, the project staff has been invited to participate as members of the DOH advisory group's maternal task team. Other donors such as DfID have already committed funds to reproducing the booklet "Ukuba Umzali".

The Department of Health KwaZulu Natal MCH has approached the RHRU, in partnership with the FRONTIERS Program of Population Council, to assist them to plan for creating conditions for an evidence-based antenatal care package in KwaZulu Natal. This would include lessons learned from the MiM study in addition to other local and international evidence. The main objective of this proposed support would be to develop comprehensive provincial guidelines for antenatal care.

\section{SUMMARY}

The intervention aimed to change attitudes of clients, providers and men that have been culturally entrenched for generations. It is encouraging to see that a number of men did come for counseling despite the structural limitations and accessibility of the counseling service. Had the intervention been in place for a longer period or supported by mass communication efforts to encourage men to come to the clinic a larger impact may have been seen.

Testing most of the hypotheses found little or no difference between the control and intervention groups. There may be several reasons for this. A number of aspects influenced both the control and intervention sites beyond the intervention activities. The same supervisors and managers were responsible for both intervention and control clinics, and there may have been contamination in terms of improved service delivery. Prince Mishyeni Memorial Hospital served both control and intervention groups, resulting in comparable exposure to counseling to initiate postpartum family planning. Providers at the hospital were positive about the intervention and reorganized their labour waiting room to accommodate men who wished to attend the birth, which may have included the partners of women in the control group. Finally, the same laboratory services were utilized by both groups for syphilis testing. The improvements made during the intervention to transport and turnaround likely affected both the control and intervention sites. 
Clinic statistics were collected at the outset of the study in order to match clinics and randomly assign them to the treatment groups. Once recruitment of participants began, it became clear that the clinic records were not accurate, and as a result some of the clinics could not achieve the expected numbers of participants due to far lower client loads then expected. This affected the significance of the results as one pair of clinics provided such low numbers that no significant difference could be seen in any component of the study hypotheses and this further affected the significance level of the other matched pairs (see Appendix 4). The study design was such that all intervention couples were included if interviewed at follow-up regardless of their exposure and therefore any positive effect among men who were exposed to the couple counseling may have been diluted by those who were not exposed.

Despite this, the intervention was both feasible and relevant. Among couples, it significantly changed communication on several important reproductive health topics. Among women, knowledge of condom as a method of dual protection condom use improved, as did partner assistance during obstetric emergencies. Almost all those who were exposed to the intervention, both couple counseling and the booklet, said it was helpful.

\section{CONCLUSION}

In conclusion, men are willing to be involved in the maternity and postnatal care of their pregnant partners. It is feasible to do this in the clinic facilities, however there are a number of challenges that must be addressed, including cultural influences, socioeconomic status, partners not living together, men not able to take time off from work and health provider attitudes. Involving men will not only improve mothers' and babies' health but also affect men's need for reproductive health.

Both men and women are interested in men's involvement during maternity care. $\mathrm{RH}$ knowledge needs improvement and men's and couples' involvement during maternity services as well as appropriate IEC materials could be a means to achieve this. It is feasible and potentially effective to have couple counseling in public sector clinics, even if only a proportion of men will be able to participate.

In order for male involvement in the maternity care of their partners to be a success the following challenges need to be addressed:

- Undertake wider community outreach so that more men can be persuaded to participate in their partners' maternity care.

- Develop ways to disseminate information that are acceptable and appropriate for the target group, both men and women.

- Reorganize public services to be friendly and flexible to both men and women who are working during the day.

- Strengthen monitoring and supportive supervision for all health services.

- Train more health provider to serve couples and to conduct couple counseling. 
- Integrate other reproductive health services such as STI, Family Planning, voluntary counseling and testing, and prevention of mother to child transmission with antenatal and postnatal care.

- Involve hospital staff to support men who may want to be with their partners during delivery. 


\section{References}

1. Department of Health . South Africa Demographic and Health Survey 1998. Pretoria, Republic of South Africa, Department of Health, and Calverton, Maryland, Macro International; 1998.

2. www.engenderhealth.org/wh/mhf/emmrwh.html. Men's Role in Women's Health. New York: EngenderHealth.

3. Reproductive Health Task Force. Assessment of reproductive health services in South Africa, focusing on Family Planning: 1994. Draft Report. Pretoria: South African Ministry of Health and Geneva: WHO-HRP; 1994.

4. Tsui, AO., Wasserheit, JN. and Haaga, J, eds. Reproductive Health in Developing Countries: Expanding Dimensions, Building Solutions. Panel on Reproductive Health, National Research Council. Washington, DC: National Academy of Sciences; 1997.

5. Dallabetta, G, Lag, M and Lamptey, P, eds. Control of Sexually Transmitted Diseases: A Handbook of the Design and Management of Programs. Arlington, VA: Family Health International, AIDSCAP;1997.

6. Ali, M.M. and Cleland J. G. The link between post natal abstinence and extra marital sex in Cote d'Ivoire. Studies in Family Planning. 2001; 32(3):214-219.

7. http://www.psishare.org/documents/AGI/824. In their own right: Addressing the sexual and reproductive health needs of men worldwide.

8. www.irinnews.org. East Africa: traditional culture spreading HIV. April 2003.

9. Department of Health. Care of pregnant women and newborns at clinics and district level. KwaZulu-Natal Department of Health; 1998.

10. Tyson H., Gibson R., Steyn R., and Trail G.. South Africa at a Glance. Editors Inc.; 2001.

11. Reproductive Rights Alliance. Towards ensuring access to reproductive choice. Johannesburg: Barometer Volume 7 May 2002.

12. Department of Health. National HIV and syphilis antenatal sero-prevalence survey in South Africa 2001. Pretoria, South Africa: Department of Health; 2002.

13. Pattinson B. (ed.). Saving Mothers. Second Report on Confidential Enquiries into Maternal Deaths in South Africa 1999-2001. Pretoria, South Africa: Department of Health; 2002.

14. Beksinska M.E., Mullick S., Kunene B., Rees H., Deperthes B. A Case Study of Antenatal Syphilis Screening in South Africa: Successes and Challenges. Sexually Transmitted Diseases 2002 (draft).

15. Hayes, R.J. and Bennett, S.. "Simple Sample Size Calculation for Cluster Randomized Trials." International Journal of Epidemiology, 1999; 28:319-326.

16. Lawoyin T.O. and Larsen U. 2002. Male sexual behavior during wife's pregnancy and postpartum abstinence period in Oyo State, Nigeria. Journal of Biosocial Science 2002; January 34(1):51-63. 
17. http://www.unfpa.org/gender/male involve.htm. Promoting a new vision of masculinity.

18. http://www.irinnews/report.asp?ReportID=33114\&SelectRegion=East Africa. East Africa: Feature-Traditional culture spreading HIV/AIDS 12 April 2003.

19. Coutsoudis A., Pillay K., Spooner E., Kuhn L. and Coovadia H.M. Influence of infant feeding patterns on early mother-to-child transmission of HIV-1 in Durban, South Africa: A prospective cohort study. The Lancet 1999; 354 (9177):471-467.

20. Interim findings on the National PMTCT pilot site lessons and recommendations www.hst.org.za; February 2002.

21. Kankasa, C., et al. Report on the rapid assessment of the UN-supported PMTCT pilot program in Zambia. New York: UNICEF. 2002.

22. Nyblade L. and Field-Nguer, M.L. Women, Communities, and the Prevention of Mother-to-Child Transmission of HIV: Issues and Findings from Community Research in Botswana and Zambia. Washington, D.C.: The International Center for Research on Women. July 2000.

23. Chopra M., Schaay N., Sanders D., Puoane T., Piwoz E, and Dunnet L.. HIV and infant feeding: Summary of findings and recommendation from a formative research study with the Khayelitsha MTCT programme, South Africa. Draft report May 2000. 


\section{APPENDIX 1.}

Materials and tools developed for the study

\begin{tabular}{|l|c|l|}
\hline Material/tool & \multicolumn{1}{|c|}{ Purpose } & \multicolumn{1}{c|}{ Target } \\
\hline $\begin{array}{l}\text { ANC } \\
\text { handbook }\end{array}$ & $\begin{array}{l}\text { Antenatal booklet containing information around key } \\
\text { areas of pregnancy, labour and delivery. }\end{array}$ & $\begin{array}{l}\text { All ANC attendees } \\
\text { at } 1^{\text {st }} \text { visit }\end{array}$ \\
\hline $\begin{array}{l}\text { Leaflets and } \\
\text { posters }\end{array}$ & $\begin{array}{l}\text { Leaflets and posters promoting male involvement at } \\
\text { the clinic }\end{array}$ & All PHC clients \\
\hline $\begin{array}{l}\text { Supervisory } \\
\text { tool }\end{array}$ & $\begin{array}{l}\text { Tool used to collect monthly information on practice } \\
\text { and record keeping. }\end{array}$ & $\begin{array}{l}\text { Clinic supervisors } \\
\text { or nurse in charge }\end{array}$ \\
\hline Registers & $\begin{array}{l}\text { a. Register developed to document syphilis test } \\
\text { results and treatment }\end{array}$ & $\begin{array}{l}\text { Nurses in ANC } \\
\text { clinic }\end{array}$ \\
\hline $\begin{array}{l}\text { Counselling register to document numbers of } \\
\text { manual }\end{array}$ & clients counselled and topics discussed & $\begin{array}{l}\text { All categories of } \\
\text { staff }\end{array}$ \\
\hline $\begin{array}{l}\text { Certificates } \\
\text { and letters }\end{array}$ & $\begin{array}{l}\text { Letters to employers requesting leave to attend couple } \\
\text { counselling }\end{array}$ & $\begin{array}{l}\text { Partners of ANC } \\
\text { attendees }\end{array}$ \\
\hline
\end{tabular}




\section{APPENDIX 2.}

Data sources, methods, and sample sizes for study

\begin{tabular}{|c|c|c|c|c|}
\hline Data Source & Main Variables Measured & $\begin{array}{l}\text { Data Collection } \\
\text { Method }\end{array}$ & Sampling & $\begin{array}{l}\text { Sample } \\
\text { Size }\end{array}$ \\
\hline & Formative research & & & \\
\hline $\begin{array}{l}\text { Clinic } \\
\text { Inventory }\end{array}$ & $\begin{array}{l}\text { Services offered; Equipment available; } \\
\text { IEC material available; Staffing; } \\
\text { Management system (including MIS); } \\
\text { Days and hours of operation }\end{array}$ & $\begin{array}{l}\text { Checklist completed } \\
\text { with assistance of } \\
\text { centre manager }\end{array}$ & $\begin{array}{l}\text { All twelve } \\
\text { clinics }\end{array}$ & 12 \\
\hline \multirow[t]{2}{*}{$\begin{array}{l}\text { Syphilis case } \\
\text { study }\end{array}$} & $\begin{array}{l}\text { Review of management of antenatal } \\
\text { syphilis screening programme }\end{array}$ & $\begin{array}{l}\text { Key informant } \\
\text { interviews, focus group } \\
\text { discussions with clients, } \\
\text { client flow analysis, exit } \\
\text { interviews with clients } \\
\text { and observations of } \\
\text { consultations }\end{array}$ & & 9 facilities \\
\hline & $\begin{array}{c}\text { Main study } \\
\end{array}$ & & & \\
\hline $\begin{array}{l}\text { Baseline } \\
\text { interviews }\end{array}$ & $\begin{array}{l}\text { Demographic background, knowledge } \\
\text { around STIs/HIV, FP use and } \\
\text { pregnancy. Male involvement, } \\
\text { communication with partner, } \\
\text { breastfeeding, IEC material }\end{array}$ & $\begin{array}{l}\text { Interviewer } \\
\text { administered } \\
\text { questionnaire }\end{array}$ & $\begin{array}{l}\text { First visit } \\
\text { ANC } \\
\text { clients } \\
\text { presenting } \\
\text { between } \\
10-30 \\
\text { weeks } \\
\text { gestation }\end{array}$ & $\begin{array}{l}2082 \\
\text { women } \\
\text { (interventio } \\
\text { n plus } \\
\text { control) } \\
584 \text { men } \\
\text { (control } \\
\text { only) } \\
\end{array}$ \\
\hline $\begin{array}{l}\text { Follow-up } \\
\text { interviews }\end{array}$ & $\begin{array}{l}\text { Demographic background, knowledge } \\
\text { around STIs/HIV, FP use and } \\
\text { pregnancy. Male involvement, } \\
\text { breastfeeding, IEC material }\end{array}$ & $\begin{array}{l}\text { Interviewer } \\
\text { administered } \\
\text { questionnaire }\end{array}$ & $\begin{array}{l}\text { All women } \\
\text { and their } \\
\text { partners } \\
\text { interviewed } \\
\text { at baseline }\end{array}$ & $\begin{array}{l}1423 \\
\text { women } \\
1166 \text { men }\end{array}$ \\
\hline \multirow[t]{2}{*}{$\begin{array}{l}\text { Focus group } \\
\text { discussions }\end{array}$} & $\begin{array}{l}\text { Client topics: Issues around male } \\
\text { involvement, communication, } \\
\text { knowledge of ANC services, STIs and } \\
\text { pregnancy. Perceptions of couple } \\
\text { counselling } \\
\text { Provider topics: training, male } \\
\text { involvement, couple counselling, } \\
\text { service issues }\end{array}$ & $\begin{array}{l}\text { FGDs with: clients (men } \\
\text { and women) at baseline } \\
\text { who were pre and post } \\
\text { delivery and nurses. } \\
\text { Post intervention with } \\
\text { providers }\end{array}$ & $\begin{array}{l}\text { Urban and } \\
\text { rural clinics } \\
\text { for clients } \\
\text { and nurses }\end{array}$ & $\begin{array}{l}12 \text { FGDs } \\
\text { pre } \\
\text { intervention } \\
3 \text { FGDs } \\
\text { post } \\
\text { intervention }\end{array}$ \\
\hline & Cost analysis & & & \\
\hline $\begin{array}{l}\text { Client flow } \\
\text { analysis }\end{array}$ & Time spent with clients & $\begin{array}{l}\text { Recording time spent of } \\
1^{\text {st }} \text { and repeat visit } \\
\text { clients during different } \\
\text { components of the ANC } \\
\text { visit }\end{array}$ & $\begin{array}{l}\text { All control } \\
\text { and } \\
\text { intervention } \\
\text { clinics }\end{array}$ & \\
\hline $\begin{array}{l}\text { Time motion } \\
\text { study }\end{array}$ & $\begin{array}{l}\text { Time spent by providers on all daily } \\
\text { activities }\end{array}$ & $\begin{array}{l}\text { Recording of all } \\
\text { activities and time } \\
\text { spent per activity of } \\
\text { staff }\end{array}$ & $\begin{array}{l}\text { All control } \\
\text { and } \\
\text { intervention } \\
\text { clinics }\end{array}$ & \\
\hline Cost data & Cost of intervention & $\begin{array}{l}\text { Collection of direct and } \\
\text { indirect costs of } \\
\text { salaries, consumables, } \\
\text { training, materials }\end{array}$ & $\begin{array}{l}\text { All costs } \\
\text { related to } \\
\text { the } \\
\text { intervention }\end{array}$ & N/A \\
\hline
\end{tabular}




\section{APPENDIX 3.}

\section{Dis tribution of client load per day}

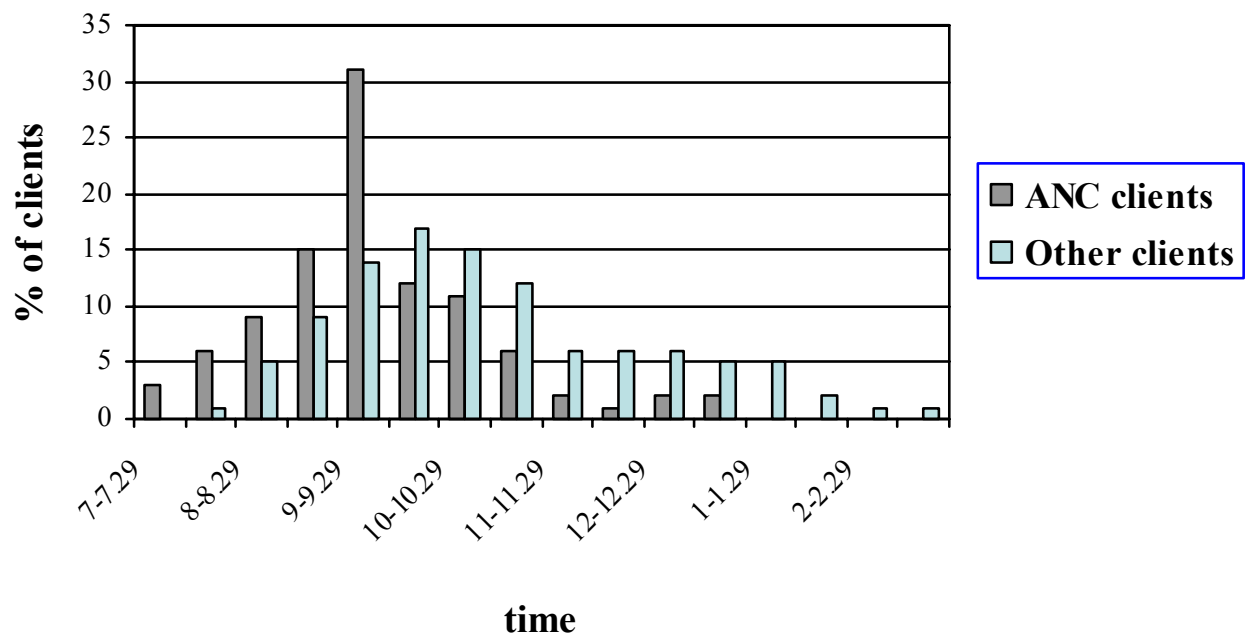




\section{APPENDIX 4.}

Summary of main indicators at follow-up by clinic

\begin{tabular}{|c|c|c|c|c|c|c|c|c|c|c|c|c|c|}
\hline \multirow[b]{2}{*}{ Control } & \multirow{2}{*}{$\begin{array}{l}\text { Women } \\
N=694\end{array}$} & \multirow{2}{*}{$\begin{array}{l}\text { Men } \\
N=558\end{array}$} & \multirow{2}{*}{$\begin{array}{l}\text { Current } \\
\text { use of } \\
\text { modern } \\
\text { method } \\
\%\end{array}$} & \multicolumn{2}{|c|}{$\begin{array}{l}\text { STI preventive } \\
\text { behavior: men } \\
\text { Condom use }\end{array}$} & \multirow{2}{*}{$\begin{array}{l}\text { Knowledge } \\
\text { of dual } \\
\text { protection }\end{array}$} & \multicolumn{2}{|c|}{$\begin{array}{l}\text { Syphilis } \\
\text { testing and } \\
\text { management }\end{array}$} & \multicolumn{2}{|c|}{$\begin{array}{l}\text { Inter-spousal } \\
\text { communication } \\
\text { and male } \\
\text { involvement }\end{array}$} & \multirow{2}{*}{$\begin{array}{l}\begin{array}{l}\text { Ever } \\
\text { Breastfed }\end{array} \\
\text { Breastfed } \\
\%\end{array}$} & \multicolumn{2}{|c|}{$\begin{array}{l}\text { Danger signs } \\
\text { knowledge }\end{array}$} \\
\hline & & & & $\begin{array}{l}\text { Regular } \\
\text { partner } \\
\%\end{array}$ & $\begin{array}{l}\text { Use } \\
\text { last } \\
\text { sex } \\
\%\end{array}$ & & $\begin{array}{l}\text { Had } \\
\text { blood } \\
\text { test } \\
\%\end{array}$ & $\begin{array}{l}\text { Knew } \\
\text { test for } \\
\text { syphilis } \\
\%\end{array}$ & STI \% & FP \% & & $\begin{array}{l}\text { Bleeding } \\
\%\end{array}$ & $\begin{array}{l}\text { High } \\
\text { blood } \\
\text { pressure } \\
\%\end{array}$ \\
\hline Clinic 1 & 5 & 2 & 100 & 50 & 100 & 40 & 100 & 40 & 60 & 60 & 100 & 40 & 100 \\
\hline Clinic 2 & 11 & 6 & 83 & 100 &.- & 45 & 100 & 45 & 82 & 91 & 100 & 64 & 55 \\
\hline Clinic 5 & 146 & 119 & 89 & 37 & 41 & 43 & 91 & 62 & 71 & 76 & 98 & 43 & 54 \\
\hline Clinic 6 & 219 & 194 & 88 & 50 & 13 & 62 & 92 & 67 & 66 & 74 & 98 & 46 & 59 \\
\hline Clinic mean & & & 90 & 46 & 22 & 57 & 94 & 67 & 64 & 70 & 98 & 50 & 55 \\
\hline Intervention & $N=729$ & $N=608$ & & & & & & & & & & & \\
\hline Clinic 7 & 14 & 7 & 80 & 29 & 50 & 36 & 100 & 86 & 57 & 64 & 100 & 36 & 79 \\
\hline Clinic 8 & 63 & 32 & 92 & 25 & 20 & 62 & 100 & 70 & 59 & 75 & 100 & 38 & 63 \\
\hline$P$ value & & & 0.7 & 0.1 & $0.02^{*}$ & $0.02^{*}$ & 0.07 & 0.06 & 0.4 & 0.8 & 0.1 & 0.09 & 0.5 \\
\hline
\end{tabular}

${ }^{*}$ Statistically significant difference between clinic means in the control and intervention groups $<p$ 


\section{APPENDIX 5.}

\section{Presentations at Scientific Meetings}

1. Involving men in antenatal and postnatal care. Zondi S, Kunene B, Beksinska M, Mthembu N, and Mullick S. $10^{\text {th }}$ Reproductive Health Priorities Conference, Johannesburg, South Africa, October 2003.

2. Men in maternity strategy to educate couple on sexual reproductive health related issues. Kunene B, Beksinska M, Mullick S, Mthembu N, and Zondi S. $10^{\text {th }}$ Reproductive Health Priorities Conference, Johannesburg, South Africa, October 2003.

3. Impact of an intervention on male partners of antenatal attendees in South Africa: implication for an expanded antenatal care package. Zondi S, Kunene B, Beksinska M, Mullick S, and Mthembu N. $10^{\text {th }}$ Reproductive Health Priorities Conference, Johannesburg, October 2003.

4. Risk perception for sexually transmitted infections and HIV pre and post intervention. Kunene B, Mullick S, Beksinska M, Adamchak S, Ottolenghi E, Kleinshmidt I, Zondi S and Mthembu N. International Conference on AIDS and STIs in Africa, Nairobi, Kenya, October 2003.

5. Impact of an intervention on male partners of antenatal attendee in South Africa: implications for an expanded antenatal care package. Mullick S, Kunene B, Beksinska M, Adamchak S, Ottolenghi E, Kleinshmidt I, Zondi S and Mthembu N. International Conference on AIDS and STIs in Africa, Nairobi, Kenya, October 2003.

6. Involving men in antenatal care: Factors associated with compliance. Mullick S, Kunene B, Beksinska M, Adamchak S, Ottolenghi E, Kleinshmidt I, Zondi S and Mthembu N. International Conference on AIDS and STIs in Africa, Nairobi, Kenya, October 2003.

7. Involving men in antenatal care: impact on male partners of antenatal care clients . Zondi S, Kunene B, Mullick S, Beksinska M, Adamchak S, Ottolenghi E, Kleinshmidt I and Mthembu N. International Conference on AIDS and STIs in Africa, Nairobi, Kenya, October 2003.

8. Involving men in antenatal and postnatal care: The Men in Maternity (MiM) Project in South Africa. Kunene B, Beksinska M, Zondi S, Mullick S, Kleinshmidt I, Adamchak S, and Ottolenghi E. Reaching Men to Improve Reproductive and Sexual Health for All Conference. Dulles, Virginia, September 2003.

9. New experimental models of providing antenatal care. Kunene B, Beksinska M, Mullick S, Chege J, Mthembu N, and Zondi, S. Joint Dissemination Workshop of 
Frontiers in Reproductive Health Program, Population and Reproductive Health Research Unit, and KwaZulu-Natal Department of Health. Durban, South Africa, June 2003.

10. Context Matters: Men in Maternity Research in India and South Africa. Adamchak S, Beksinska M, Kunene B, Mishra A, Ottolenghi E, and Varkey LC. Global Health Council, Washington, DC, May 2003.

11. Does men's involvement improve women's knowledge and care seeking for obstetric danger signs? Ottolenghi E, Varkey LC, Das, A, Mishra, A, Beksinska, M, Kunene B, and Adamchak S. Global Health Council, Washington, DC, May 2003.

12. Abstinence pre and post delivery: does it happen, and is it a potential risk factor for STI and HIV/AIDS? Kunene B, Beksinska M, Mullick S and Zondi S. Perinatal Priority Conference. Bloemfontein, South Africa, March 2003.

13. Men in Maternity: What is in it for both women and men? Kunene B, Beksinska M, Mullick S and Zondi S. AMINITARE Conference. Johannesburg, South Africa, February 2003.

14. HIV risk perception among antenatal women: Accuracy and effect on sexually transmitted infection/HIV preventive behaviour. Kunene B, Beksinska M, Mullick S, Chege J, Mthembu N, and Zondi S. $9^{\text {th }}$ Reproductive Health Priorities Conference. Wild Coast, South Africa, October 2002.

15. Experience of gender based violence amongst women seeking antenatal care services: What are implications for STI/HIV prevention behaviour? Chege J, Kunene B, Mullick S, Beksinska M, Mthembu N, and Zondi S. $9^{\text {th }}$ Reproductive Health Priorities Conference, Wild Coast, South Africa, October 2002.

16. Unplanned pregnancies: Review of the risk factors and extent of the problem. Beksinska M, Kunene B, Mullick S, Chege Jane, Mthembu N, and Zondi S. $9^{\text {th }}$ Reproductive Health Priorities Conference, Wild Coast, South Africa, October 2002.

17. A comparison of adolescent and non-adolescent women attending antenatal care clinics: Implications for adolescent friendly antenatal services. Kunene B, Mullick $\mathrm{S}$, Beksinska M, Chege J, Mthembu N, and Zondi S: $9^{\text {th }}$ Reproductive Health Priorities Conference, Wild Coast, South Africa, October 2002.

18. Pre and postpartum abstinenc: Is it a risk factor for sexually transmitted disease including HIV? Zondi S, Mullick S, Beksinska M, Chege, Mthembu N, Kunene B. $9^{\text {th }}$ Reproductive Health Priorities Conference, Wild Coast, South Africa, October 2002.

19. Syphilis screening and management in antenatal care: Case studies from Kenya and South Africa. Mullick S, Maggwa N, Askew I, Kunene B, Bekinska M. $8^{\text {th }}$ 
Reproductive Health Priorities Conference, Drukensburg, South Africa, August 2001.

20. Antenatal care: service delivery issues. Mullick S, Janowitz B, Kunene B, Maggwa N, Cuthbertson C, Johnson L, and Beksinska M. $8^{\text {th }}$ Reproductive Health Priorities Conference, Drukensburg, South Africa, August 2001.

21. Challenges of reaching couples with RH Services, including STI/HIV. Kunene B, Beksinska M, Mullick S, Maggwa N, Mthembu N, and Zondi S. $8^{\text {th }}$ Reproductive Health Priorities Conference, Drukensburg, South Africa, August 2001.

22. Improving quality of care: The role of a supportive supervisory checklist. Mthembu N, Kunene B, Maggwa N, Gumede A, et al.. $8^{\text {th }}$ Reproductive Health Priorities Conference, Drukensburg, South Africa, August 2001.

23. Challenges of involving in the reproductive health: Men in Maternity. Kunene B, Beksinska M, Mullick S, Maggwa N, Mthembu N, and Zondi S. National Initiative Cross-site Symposium, Durban, South Africa, July 2001.

24. Syphilis screening and management during antenatal care in South Africa. Kunene B, Beksinska M, Mullick S, Mosery F.N. $7^{\text {th }}$ Reproductive Health Priorities Conference, Cape Town, South Africa, August 2000. 